\title{
The Role of Cortical Activity in Experience-Dependent Potentiation and Depression of Sensory Responses in Rat Barrel Cortex
}

\author{
Helen Wallace, Stanislaw Glazewski, Katherine Liming, and Kevin Fox \\ Cardiff School of Biosciences, Cardiff University, Cardiff, CF10 3US Wales, United Kingdom
}

The role of cortical activity in experience-dependent cortical plasticity was studied in the rat barrel cortex. Plasticity was induced by depriving every other whisker in a chessboard pattern, which is known to cause depression of responses to deprived whisker stimulation and potentiation of responses to spared whisker stimulation. Postsynaptic activity was blocked by muscimol released from elvax slow-release polymer located under the dura and over the barrel field. Spared whisker responses potentiated 2.5-fold in layer II/III and 2.9-fold in layer IV of the near-neighbor barrel in animals implanted with salineelvax. In contrast, in whisker-deprived animals implanted with muscimol-elvax, responses were indistinguishable from those in undeprived animals. Similarly, in the spared barrel itself, spared whisker responses potentiated 1.3-fold in layer IV in animals implanted with saline-elvax but not at all in muscimol- treated animals. Whiskers that were deprived and then allowed to regrow showed depressed responses in saline-elvax-treated animals, in which $40 \%$ of the cells in layer II/III and $26 \%$ in layer IV were unresponsive to their principal whisker. These values fell to 17 and $3 \%$ for layers II/III and IV, respectively, in muscimol-treated animals, and the response magnitude distributions were indistinguishable from undeprived cases. Cortical activity block had no acute effect on the ventroposteriomedial nucleus responses and had a transient facilitatory effect after $4 \mathrm{~d}$ of muscimol treatment, which returned to baseline as the muscimol treatment wore off. We conclude from these studies that cortical activity is required for potentiation and depression of sensory responses in barrel cortex.

Key words: synaptic plasticity; thalamus; cerebral cortex; inhibition; elvax; somatosensory
The barrel cortex of the rodent contains the somatosensory representation of the whiskers (Woolsey and Van der Loos, 1970). The columnar organization is particularly well defined in this area, because the whiskers are discrete sensory units projecting to discrete cortical locations, albeit with some physiologically relevant divergence. Barrel cortex plasticity has been described by a number of laboratories, which have used its overt columnar organization to determine where plasticity is expressed (Simons and Land, 1987; Fox, 1992; Diamond et al., 1993). There is evidence that plasticity can occur in pathways projecting within cortical columns as well as between cortical columns (Diamond et al., 1993; Fox, 1994; Glazewski and Fox, 1996; Finnerty et al., 1999; Barth et al., 2000), and there is evidence that plasticity can involve increases in sensory responses in some locations while decreases occur elsewhere (Glazewski et al., 1998; Polley et al., 1999; Skibinska et al., 2000).

The role of activity in the induction of plasticity in the barrel cortex is not so well known. There is certainly evidence that cortical neuronal activity must be involved in some manner because the changes in transmission that occur as a result of sensory deprivation are produced by changes in sensory input from the whiskers (Armstrong-James et al., 1994; Li et al., 1995) and occur within the cortex (Fox, 1994). But it is not known whether depression requires activity or is simply a passive decay of sensory response because of inactivity. When this question has been

\footnotetext{
Received Aug. 24, 2000; revised Feb. 27, 2001; accepted March 14, 2001.
}

This work was supported by National Institutes of Health Grant NS27759 (K.F.) and by a grant from the Medical Research Council (K.F.). We gratefully acknowledge the assistance of Mervyn McKenna for all histology and Paul Chapman and Frank Sengpiel for critical reading of the text.

Correspondence should be addressed to Kevin Fox at the above address. E-mail: foxkd@cardiff.ac.uk.

Copyright (C) 2001 Society for Neuroscience $\quad 0270-6474 / 01 / 213881-14 \$ 15.00 / 0$ addressed in the visual cortex, the answer has not always been intuitively obvious. For example, if synaptic activity is blocked with muscimol in the visual cortex and the animal monocularly deprived, the responses to the deprived eye increase, and the responses to the open eye weaken (Reiter and Stryker, 1988; Hata and Stryker, 1994). It is important to see whether this rule applies to plasticity in other cortical areas.

A second issue requiring resolution is the locus of experiencedependent plasticity. The main thalamic input to the cortex (VPm) does not show evidence of plasticity in response to whisker deprivation (Glazewski et al., 1998). However, it is conceivable that a subcortical pathway yet to be investigated is involved in plasticity expression. Rather than look through each possible nucleus individually and still run the risk of missing an undiscovered pathway, a direct strategy would be to block cortical activity and see whether plasticity could still be expressed in the cortex after deprivation.

We therefore looked at the role of synaptic activity in barrel cortex plasticity by imposing a chessboard pattern of deprivation

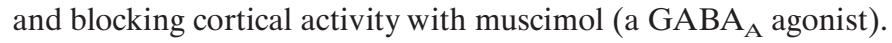
The drug was released from a piece of elvax slow-release polymer implanted on the surface of the cortex beneath the dura. Recent studies have shown that inactivating cortex can itself cause changes in subcortical receptive fields (Ergenzinger et al., 1998; Krupa et al., 1999). We therefore also looked at the effect of the implant on thalamic VPm responses to whisker stimulation. The results provide evidence of the involvement of postsynaptic cortical activity in experience-dependent potentiation and depression of sensory responses in barrel cortex.

\section{MATERIALS AND METHODS}

Subjects. Adolescent Long-Evans rats aged 28-35 d at implantation were recorded between 42 and $49 \mathrm{~d}$ after birth in these experiments. Cortical 
Table 1. The number of cells recorded in the barrel cortex categorized by anatomical location and drug treatment

\begin{tabular}{|c|c|c|c|c|c|c|}
\hline \multirow{2}{*}{$\begin{array}{l}\text { Layer } \\
\text { Barrel }\end{array}$} & \multicolumn{3}{|l|}{$\mathrm{II} / \mathrm{III}$} & \multicolumn{3}{|l|}{ IV } \\
\hline & Spared & Deprived & Undeprived & Spared & Deprived & Undeprived \\
\hline Saline-elvax & 35 & 55 & 109 & 34 & 49 & 79 \\
\hline Muscimol-elvax & 42 & 54 & 94 & 34 & 67 & 91 \\
\hline Total & 77 & 109 & 203 & 68 & 116 & 170 \\
\hline
\end{tabular}

recordings were made from 27 rats with chronic elvax implants (see Table 1). Muscimol diffusion was characterized in a further 19 rats, and VPm recordings were made from 13 animals.

Deprivation. Whiskers were deprived in a chessboard pattern by removing every other whisker in a row. Animals not receiving implants were anesthetized with metofane (Mallinckrodt Veterinary, Inc., Mundelein, IL), and the following whiskers were removed by applying gentle tension [as described previously (Wallace and Fox, 1999a)]: E2, E4, and E6; D1, D3, and D5; C2, C4, and C6; B1 and B3; and A2 and A4. Deprivations were started between the ages of 28 and $35 \mathrm{~d}$ after birth. Deprivation was maintained for $7 \mathrm{~d}$, and then the whiskers were allowed to regrow for $6-8 \mathrm{~d}$ before recording. For the purpose of this report we define the following terms: "spared" means a whisker that was not removed from an animal that had other whiskers removed; "deprived" means a whisker that was removed and later allowed to regrow; and "undeprived" means a whisker that was not deprived in an animal that did not have any whiskers removed.

Implantation surgery. Animals receiving implants were induced with metofane, and short-term anesthesia was maintained with short-acting barbiturate (Brietal; Animal Care, Ltd.). Wound margins were treated with local anesthetic (Lignocaine; C-Vet). In some cases, deprivations were imposed as described above. A channel was drilled in the skull parallel to the midline and $\sim 4 \mathrm{~mm}$ lateral to it. A slit was made in the dura to introduce the elvax (see Fig. 1). The elvax was pushed more lateral with a fine pair of forceps to lie above the medial aspect of the barrel cortex. The area was treated with topical antibiotics (Aureomycin and Cynamid) and sutured closed. The elvax was usually left in place from the day of implantation until the day of recording $(14 \mathrm{~d})$. Figure 2 shows the timing of muscimol-doped elvax implantation relative to the whisker deprivation and regrowth period.

Recording and anesthesia. For the final recording session, anesthesia was induced with metofane and maintained with urethane $(1.5 \mathrm{gm} / \mathrm{kg}$ of body weight; Sigma, St. Louis, MO). Anesthetic depth was monitored throughout the experiment by testing reflexes and observing the sponta- neous firing rate of neurons. Supplements of urethane were administered to maintain a state in which the hindlimb withdrawal reflex was sluggish but present and the layer $\mathrm{V}$ neurons generated bursts of spikes in the 1-2 $\mathrm{Hz}$ range (Fox and Armstrong-James, 1986).

For cortical recordings, a small craniotomy was made between 4 and $7 \mathrm{~mm}$ lateral to the midline and 1 and $4 \mathrm{~mm}$ caudal to bregma by careful drilling. The dura was left intact except where small holes $(100-200 \mu \mathrm{m})$ were made to allow the electrode access to the brain. For VPm recordings, a craniotomy was made between 2 and $4 \mathrm{~mm}$ lateral to the midline and 1 and $3.5 \mathrm{~mm}$ caudal to bregma. The dura was retracted to introduce the electrode.

Cortical and thalamic neurons were recorded using single-barrel carbon fiber microelectrodes (Armstrong-James et al., 1980). Electrodes were lowered vertically during thalamic recording and angled at $\sim 20^{\circ}$ to the vertical axis in the mediolateral plane during recording from the cortex. The signal was bandpassed between $600 \mathrm{~Hz}$ and $6 \mathrm{kHz}$, and spikes were discriminated using a voltage window discriminator. Spike shape was also monitored to ensure that the recording was derived from a single neuron. Poststimulus time histograms and raster plots were generated on-line and stored for later analysis using Spike 2 software (CED, Cambridge, UK).

For the studies in which cortical responses were acutely inactivated with muscimol, field potentials in response to whisker stimulation were monitored at a depth of 500-700 $\mu \mathrm{m}$ (bandwidth, $0.1 \mathrm{~Hz}$ to $20 \mathrm{kHz}$ ).

Stimulus. The stimulus was a $200 \mu \mathrm{m}$ vertical deflection of a single vibrissa $\sim 10 \mathrm{~mm}$ from the face, delivered at $1 \mathrm{~Hz}$. The stimulator was a fast piezoelectric bimorph wafer attached to a lightweight glass capillary touching the vibrissa. For a complete description, see Armstrong-James and Fox (1987).

Sampling. Neurons were sampled evenly approximately every $100 \mu \mathrm{m}$ throughout the cortical penetrations and approximately every $50 \mu \mathrm{m}$ in the thalamic penetrations. Cortical cells were isolated by moving the electrode to the next position and discriminating a cell using its spontaneous activity. The electrode position was then adjusted by $\sim 10-20 \mu \mathrm{m}$

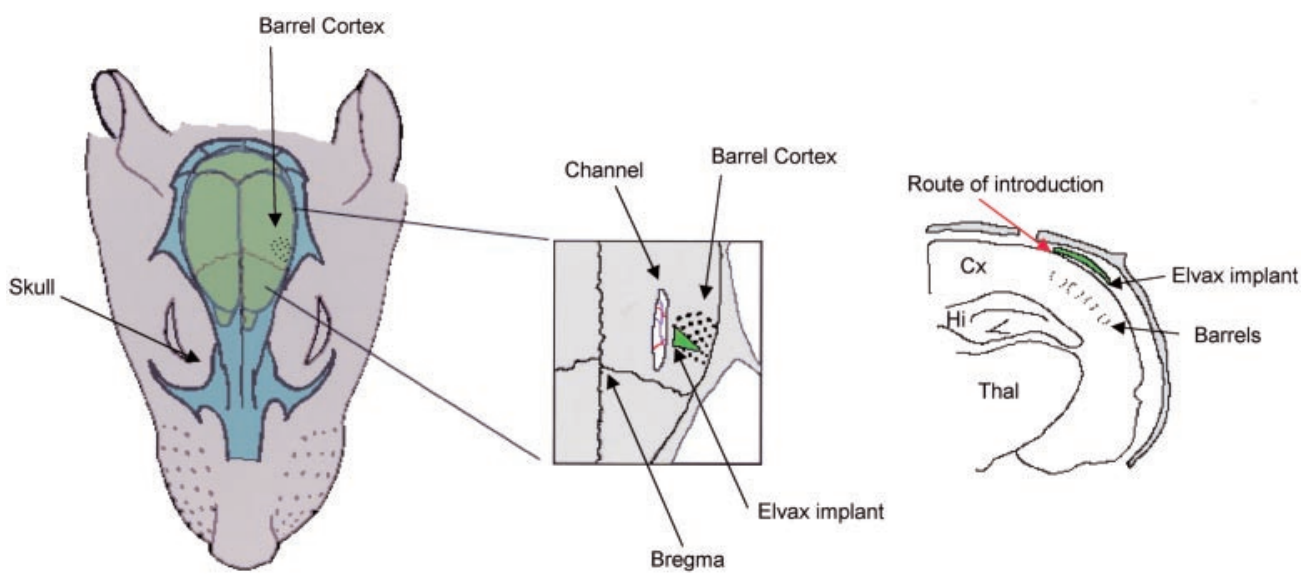

Figure 1. Implantation of elvax slow-release polymer. The elvax is implanted under the dura and over the barrel field using a medial approach. Left, The barrel cortex is located $\geq 5 \mathrm{~mm}$ lateral to the midline (note label for barrel cortex; black dots represent barrels). Middle, A plan view is shown. A small channel is drilled at $\sim 4 \mathrm{~mm}$ lateral to the midline, and the elvax is inserted through the channel under the dura so that it lies above the barrel cortex. The elvax implant (green triangle) is typically triangular in shape. Right, A coronal view is shown. The elvax is inserted through the channel in the skull in the direction indicated by the red arrow. The elvax is pliable and thin $(70 \mu \mathrm{m})$ and fits under the dura (not shown for clarity). The elvax is maneuvered carefully in a direction lateral to the channel until it lies above the barrel cortex. This approach causes minimal trauma to the barrel cortex because the opening of the skull and the dura are distant to the barrel cortex. $C x$, Cortex; Hi, hippocampus; Thal, thalamus. 


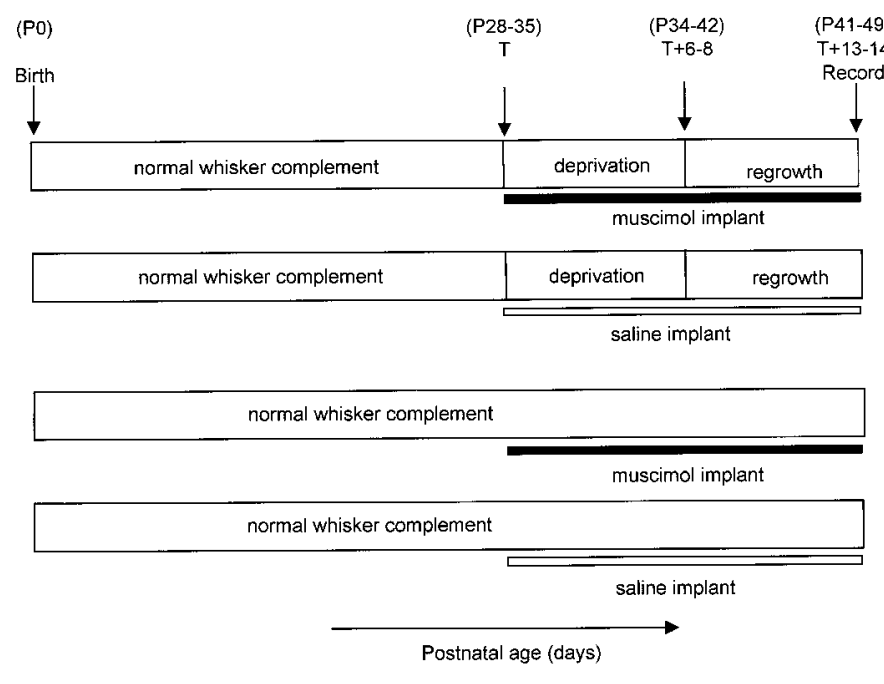

Figure 2. Time course of deprivation and relationship to elvax implantation. The age of the animal is shown increasing from left to right for four treatments: from the top, muscimol-elvax implantation plus deprivation, saline-elvax implantation plus deprivation, muscimol-elvax implantation without deprivation, and saline-elvax implantation without deprivation. Top, The animal is reared from birth with all whiskers intact. Between 28 and $35 \mathrm{~d}$ of age the procedure is started (start day = time $T$ ); on the same day elvax is implanted, and chessboard pattern deprivation is imposed. After 6-8 d of repeated whisker deprivation, the whiskers are allowed to regrow $(T+6-8)$. Within 13-14 d of implantation, recordings are made from the cortex to assess the effect $(T+13-14)$. P0, Postnatal day 0 .

to optimize discrimination. If, when a stimulus was applied, a larger spike occurred that was more easily discriminated, it was often used for study instead.

Some cells were classified as unresponsive because they showed little or no response to stimulation of their principal whisker. Nevertheless, these cells were discovered and therefore form part of the sample because they showed responses to surround receptive field (SRF) whiskers and/or they showed spontaneous activity.

Histology. At the end of recording from each penetration in the thalamus or cortex, a small focal lesion $(1.2 \mu \mathrm{A}$; DC; tip negative) was made at a site of known depth (in layer IV for cortical recordings; in a particular barreloid for V Pm recordings). If recordings had been made in the cortex, the cortex was flattened and processed for cytochrome oxidase histology as described previously (Wong-Riley, 1979; Fox, 1992), and the location of each recording penetration was identified within the barrel field. In this way, we could identify the principal vibrissa for each recorded cell. If thalamic recordings were made, coronal sections were cut, and the site of recording was identified within the VPm from cytochrome oxidase histology. It was possible to identify barreloids from such sections but not the identity of individual barreloids. The D2 barreloid was usually found $4.0-4.5 \mathrm{~mm}$ below the dura.

Manufacture of elvax and release of muscimol. Tritiated muscimol (250 $\mu \mathrm{Ci}$; Tocris) was used to measure muscimol release from elvax slowrelease polymer. Elvax was manufactured as described previously (Fox et al., 1996). The aqueous phase comprised $3 \%$ of the total solvent volume and contained $866 \mathrm{~mm}$ muscimol (hot:cold, $250 \mu \mathrm{Ci}: 866 \mathrm{~mm}$ ). The aqueous solution was sonicated to produce a fine emulsion in the elvaxmethylene chloride solution before the emulsion was poured into a $5 \mathrm{ml}$ mold on dry ice. The resultant puck of elvax was dried for $4 \mathrm{~d}$ at $4^{\circ} \mathrm{C}$ before being sectioned into $70 \mu \mathrm{m}$ sections by use of a freezing microtome.

Sections of elvax were placed in $1 \mathrm{ml}$ of water and allowed to release for periods of up to 2 months. The eluate was mixed with BCS scintillant (Amersham) for liquid scintillation counting (Packard 4530 counter). The values from triplicates were averaged and plotted to estimate release.

Muscimol diffusion within the cortex. A small well was made above the cortex by first protecting the surface of the cortex with a small plug of gelfoam and then covering the exposed area with agar. When the agar had set, the sterispon plug was removed leaving a small agar well above the cortex. The dura was retracted over several square millimeters, and muscimol dissolved in PBS was applied to the surface of the brain at known concentrations (100 or $200 \mu \mathrm{M}$; pH 7.4). The well of muscimol was replenished several times during the recording session to keep the concentration constant. The effect of muscimol was measured by plotting poststimulus time histograms (PSTHs) for the principal whisker response of cells at known depths. The depth was verified by making two lesions, one at the top and one at the bottom of the penetration, at the end of the experiment and reconstructing the penetration from the histology.

The time at which muscimol extinguished the principal whisker response was plotted and compared with theoretical curves for diffusion using the following equation:

$$
C_{x, t}=C_{0} \operatorname{erfc}\left\{x /\left(D^{*} t\right)^{1 / 2}\right\},
$$

where $C_{x, t}$ is the concentration at a given depth and time, $C_{0}$ is the concentration at the surface, erfc is the error function complementary, $x$ is the depth within the cortex, $t$ is time, and $D^{*}$ is the modified diff usion coefficient for muscimol. The diffusion coefficient for muscimol was taken to be $\sim 8.7 \times 10^{-6} \mathrm{~cm}^{2} / \mathrm{sec}$ and was modified by values for tortuosity and volume fraction according to the following equation:

$$
D^{*}=\frac{\alpha D}{\lambda^{2}},
$$

where $\alpha$ is the volume fraction $(\sim 0.21)$ and $\lambda$ is tortuosity $(\sim 1.55)$ (Nicholson and Phillips, 1981).

Analysis. All data were analyzed using PSTHs and latency histograms. The response magnitude to stimulation of a particular vibrissa was defined as the number of spikes per stimulus occurring between 5 and 50 msec after the stimulus for the cortex (and between 3 and $50 \mathrm{msec}$ for the thalamus) minus the spontaneous activity occurring during an identical time period before the stimulus. The modal latency was used to describe the response latency of the neuron. For a complete description see Armstrong-James and Fox (1987).

Statistical analysis. In general, statistical tests that compared one group of animals against another group were used in preference to tests that compared data pooled from different animals. The rationale behind this is that the animals were receiving the treatment rather than the individual cells. In this way, unintended differences in treatment are taken into account in the analysis, and the results are not biased one way or the other by more cells being recorded from one animal than another. Furthermore, the degrees of freedom are not artificially inflated by sampling many cells with a similar property.

Response distribution histograms were constructed for all cells recorded within a particular treatment group. In addition, the average response to a particular class of whisker (e.g., spared) was calculated as an average for each animal. The per-cell distributions were used for descriptive statistics only, and the per-animal distributions were used for analysis. The normality of the per-animal distributions was assessed with the Schapiro-Wilk test. Parametric statistics were used to compare groups where possible (two-way ANOVAs and $t$ tests). Where response magnitudes were not normally distributed, nonparametric test were used instead (Mann-Whitney $U$ test). The latter was most often the case for layer II/III cells and for cells responding to stimulation of deprived (regrown) whiskers.

\section{RESULTS}

We recorded responses from 389 cells in layer II/III and 354 cells in layer IV of the barrel cortex. Of these, 382 were recorded in animals receiving a muscimol-loaded elvax implant, and 361 were in animals receiving a saline-loaded elvax implant. Table 1 shows the numbers of cells recorded in spared and deprived barrels as well as the number of cells recorded in undeprived animals.

In addition, we made recordings from 74 cortical locations to test the time course of muscimol diffusion within the cortex (see Appendix) and from $160 \mathrm{VPm}$ cells to test the effect of cortical muscimol treatment on VPm responses.

\section{The effect of implanting elvax alone on normal responsivity and plasticity}

We needed to implant elvax slow-release polymer under the dura to deliver muscimol to the cortex. To assess whether the implant 
LII/III No elvax deprived LIV

Figure 3. Depression of principal whisker responses of deprived (regrown) whiskers. Response magnitude distributions are shown for three treatment groups: top, deprived, no elvax; middle, deprived, saline-elvax; bottom, undeprived, salineelvax. Distributions are shown for layer II/III cells (left) and layer IV cells (right). The response magnitude distributions are shown for each cell in a treatment group (main histograms; gray bars). The inset histograms (white bars) show the distribution of average response magnitudes for each animal. Top, Deprived animals without implants exhibit distributions skewed to the left, reflecting a decrease in responsiveness after deprivation. Middle, Deprived animals receiving saline-elvax implants also show distributions skewed to the left, showing that the implants do not prevent depression. Note that $40 \%$ of cells in layer II/III and $25 \%$ in layer IV are unresponsive to principal whisker stimulation compared with 40 and $22 \%$ for deprived animals without implants (top). Bottom, Responses are significantly higher in undeprived animals receiving salineelvax implants. The distributions are not different between animals with salineelvax implants and animals without any implants (see Results). Bin width, 10 spikes per 50 stimuli. Labels of all axes are shown on the bottom left. LII/III, Layer II/III; $L I V$, layer IV.
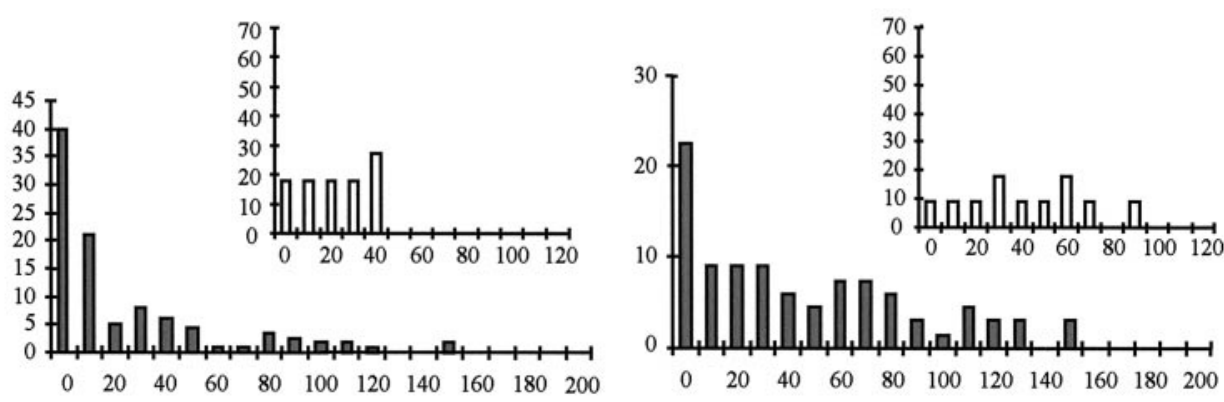

Saline-elvax deprived
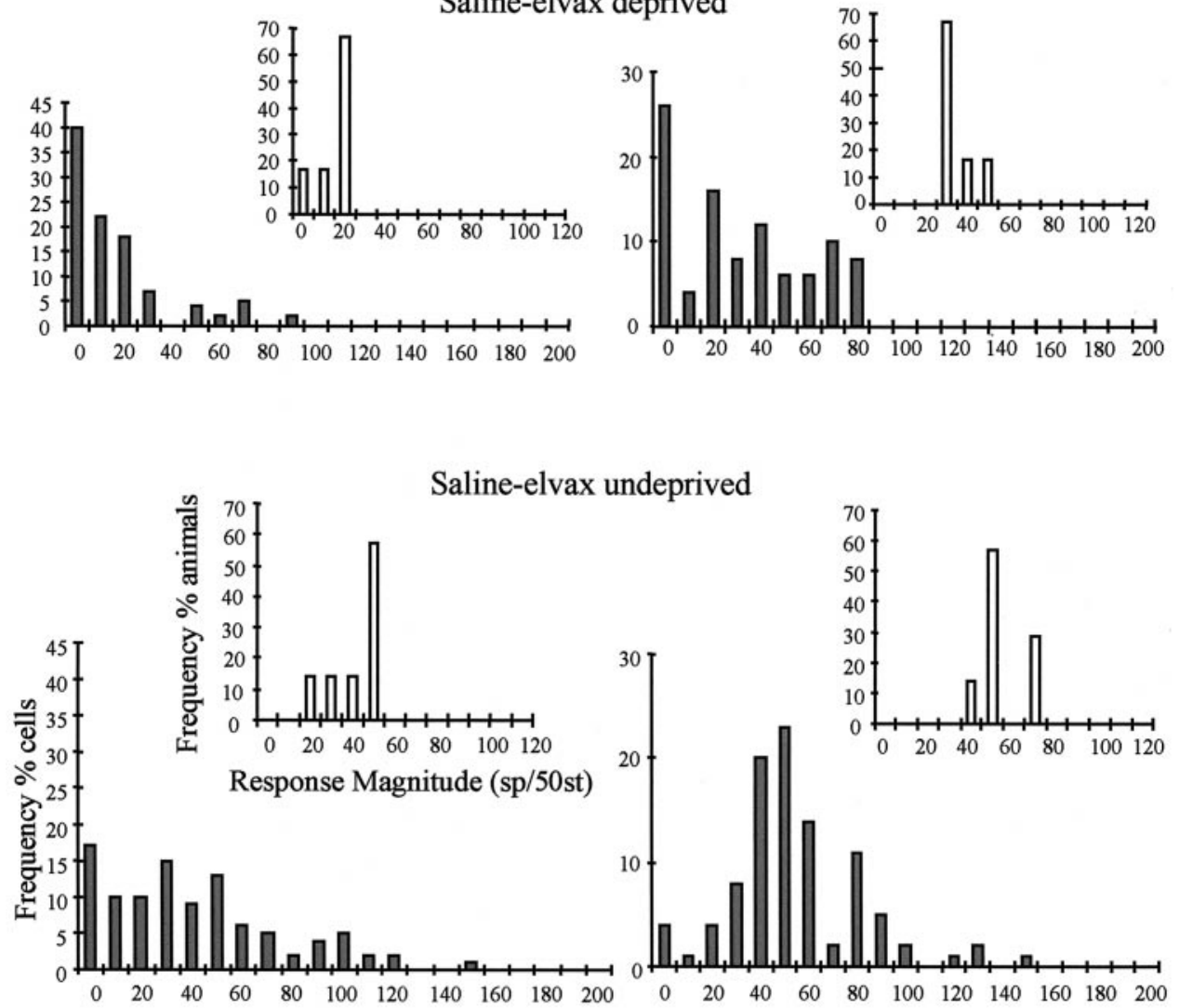

Response Magnitude (spikes per 50 stimuli) or the implantation procedure alone had any effect on the normal responsivity or plasticity of cortical cells, we studied the effect of implanting elvax loaded with saline (saline-elvax) on cortical responses in undeprived and deprived animals (see Fig. 3).

\section{Undeprived animals: principal whisker responses}

The presence of a saline-elvax implant for a period of $14 \mathrm{~d}$ had no discernible effect on the responses of neurons in layers II/III to stimulation of the principal vibrissa. Normally, responses to principal whisker stimulation in undeprived animals are $\sim 51.0 \pm 5.0$ spikes per 50 stimuli (sp/50st; mean \pm SEM) for layer II/III cells (Table 2). This value is practically identical to that for animals receiving a saline-elvax implant (45.5 $\pm 4.3 \mathrm{sp} / 50 \mathrm{st})$. Figure 3 shows the pooled distributions for responses recorded in undeprived animals with saline-elvax together with the distribution of the average response of each animal (see insets). Comparison of response distributions shows that principal whisker responses in saline-elvax-treated animals are not significantly different from those in animals without implants $[p=0.48 ; U(7,7)=19$, MannWhitney $U$ test].

A similar effect was found for layer IV. Normally, responses to principal whisker stimulation are $76 \pm 7 \mathrm{sp} / 50$ st. In saline-elvaxtreated animals the value appeared slightly lower at $59 \pm 5.3$ $\mathrm{sp} / 50 \mathrm{st}$ (Table 2). These values were found not to be significantly different $[t(12)=2.08 ; p>0.06]$. 


\begin{tabular}{|c|c|c|c|c|}
\hline Treatment & $\begin{array}{l}\text { Deprivation } \\
\text { condition }\end{array}$ & $\begin{array}{l}\text { Layer II/III } \\
\text { mean } \pm \text { SEM }\end{array}$ & $\begin{array}{l}\text { Layer IV } \\
\text { mean } \pm \text { SEM }\end{array}$ & $\begin{array}{l}\text { Number of } \\
\text { cases }\end{array}$ \\
\hline No implant & Undeprived & $51 \pm 5$ & $76 \pm 7$ & 7 \\
\hline No implant & Spared & $44.1 \pm 4.1$ & $92.2 \pm 5.15$ & 11 \\
\hline Saline-elvax & Undeprived & $45.5 \pm 4.3$ & $59 \pm 5.3$ & 7 \\
\hline Saline-elvax & Spared & $62.2 \pm 5.5$ & $80 \pm 2.0$ & 6 \\
\hline Muscimol-elvax & Undeprived & $32.5 \pm 1.9$ & $47 \pm 3.0$ & 7 \\
\hline Muscimol-elvax & Spared & $46.5 \pm 5.3$ & $53.0 \pm 3.5$ & 7 \\
\hline
\end{tabular}

Means and SEMs are treatment group averages of spikes per 50 stimuli.

\section{Undeprived animals: surround receptive field responses}

Most neurons lying within a particular barrel column are located closer to one side of that barrel column than to the other. This means that one neighboring barrel is closer to the cell than are the others. We define the closer neighboring barrel as the nearneighbor barrel and the whisker corresponding to the nearneighbor barrel as the near-neighbor whisker. We found that implanting saline-elvax had no discernible effect on nearneighbor responses, either in layer II/III or IV (Fig. 4). For layer II/III, stimulating the near-neighboring whisker produced an average response of $15.5 \pm 2.45 \mathrm{sp} / 50 \mathrm{st}$ in animals without implants (see Table 3). In animals with saline-elvax implants the near-neighbor whisker evoked responses averaging $13 \pm 1.95$ $\mathrm{sp} / 50 \mathrm{st}$, which is not significantly different from the response in unimplanted controls $[t(13)=0.79 ; p>0.5]$. Similarly, in layer IV, average values recorded in unimplanted animals $(17.1 \pm 4.38$ $\mathrm{sp} / 50 \mathrm{st})$ and in animals with saline-elvax implants $(19.2 \pm 4.3$ $\mathrm{sp} / 50 \mathrm{st})$ were not different statistically $[t(11)=0.34 ; p>0.5]$.

In summary, the presence of an elvax implant per se does not affect surround receptive field or principal whisker responses in layer II/III or layer IV.

\section{Deprived animals: potentiation}

Having examined the effect of saline-elvax implants on normal response levels, we next considered whether the implant or implantation procedure affected plasticity. In previous studies we found that the chessboard pattern of whisker deprivation causes potentiation of the spared whisker responses in three locations: near-neighbor responses in layer II/III of the deprived barrel column, near-neighbor responses in layer IV of the deprived barrel column, and principal whisker responses in layer IV of the spared barrel (Wallace and Fox, 1999a).

In layer II/III, stimulation of near-neighbor whiskers produces responses of magnitude $15.5 \pm 2.45 \mathrm{sp} / 50 \mathrm{st}$ (mean $\pm \mathrm{SEM}$ ) in undeprived animals (see Table 3 ). A period of chessboard deprivation produces a 2.2-fold increase in near-neighbor responses in the deprived barrel column to $36.5 \pm 4.7 \mathrm{sp} / 50 \mathrm{st}$ that is highly statistically significant $[t(13)=3.7 ; p=0.0003]$. Average responses to near-neighboring whisker stimulation potentiated to a similar degree (2.5-fold) in animals receiving saline-elvax implants (Fig. 4, top). In these cases, stimulation of the nearneighbor whisker produced responses of $13 \pm 1.95 \mathrm{sp} / 50 \mathrm{st}$ in undeprived and $32.5 \pm 3.5 \mathrm{sp} / 50 \mathrm{st}$ in chessboard pattern-deprived animals, and these values are significantly different $[t(11)=5.15$; $p=0.0003$.

Layer IV cells behaved in a similar way to layer II/III cells (Fig. 4). A period of chessboard pattern deprivation caused a 2.9-fold increase in near-neighbor responses from an average of $17 \pm 4.38$ $\mathrm{sp} / 50 \mathrm{st}$ in undeprived animals to $50 \pm 9.5 \mathrm{sp} / 50 \mathrm{st}$, and these values were significantly different $[t(13)=3.1 ; p=0.008]$. Normal levels of potentiation (2.4-fold increase) also occurred in animals with saline-elvax implants (see Table 3) $[t(11)=3.86 ; p=0.0026]$.

Principal whisker responses were also potentiated in the spared barrels in animals with saline-elvax implants. In layer II/III, the average response magnitude increased $\sim 1.36$-fold to $62.2 \pm 5.5$ $\mathrm{sp} / 50 \mathrm{st}$ in deprived animals compared with $45.5 \pm 4.3 \mathrm{sp} / 50 \mathrm{st}$ in undeprived animals. These values were significantly different $[U(7,7)=5 ; p=0.02]$. Similarly, in layer IV, responses were potentiated 1.35 -fold to $80 \pm 2 \mathrm{sp} / 50$ st compared with $59 \pm 3.5$ $\mathrm{sp} / 50 \mathrm{st}$ in undeprived animals $[t(11)=4.78 ; p=0.0006]$. These findings show that the control implant does not prevent potentiation (see Fig. 6).

\section{Deprived animals: depression}

To understand the responses of cortical neurons to stimulation of deprived principal vibrissae, it is necessary to consider the overall distribution of responses. Unlike the responses to undeprived vibrissae or to spared vibrissae, the distributions of responses to regrown deprived vibrissae are skewed (Wallace and Fox, 1999a). This can be seen in Figure 3. The overall pooled distribution of responses in normal undeprived animals contained very few cells that were unresponsive or poorly responsive to stimulation of their principal whisker (percent of cells with $<10 \mathrm{sp} / 50 \mathrm{st}=10 \%$ in layer II/III; note that these cells may have been responsive to surround receptive field whiskers). However, in deprived animals the distribution of response magnitudes was heavily skewed to lower response values, and the percent of unresponsive cells increased to $40 \%$ for layer II/III.

A similar effect of deprivation can be seen in Figure 3 for animals receiving a saline-elvax implant. Although just $17 \%$ are unresponsive in undeprived animals, this value increases to $40 \%$ for deprived animals. Nonparametric statistics indicate that the distribution of responses averaged for each animal is significantly different $[U(7,6)=0.5 ; p<0.03]$, which implies that the elvax implant does not prevent experience-dependent depression in this layer.

In layer IV, deprivation increased the fraction of unresponsive or poorly responding cells from $0 \%$ in undeprived animals to $23 \%$ in chessboard pattern-deprived animals. This effect was also present when deprivation was imposed on animals receiving saline-elvax implants. In this case, the number of poorly responding cells increased from $4 \%$ in undeprived to $26 \%$ in deprived animals (Fig. 3). The distributions of responses averaged for each animal (Fig. 3, inset histograms) are significantly different $[t(11)=$ $4.12 ; p<0.02]$. 
LII/III
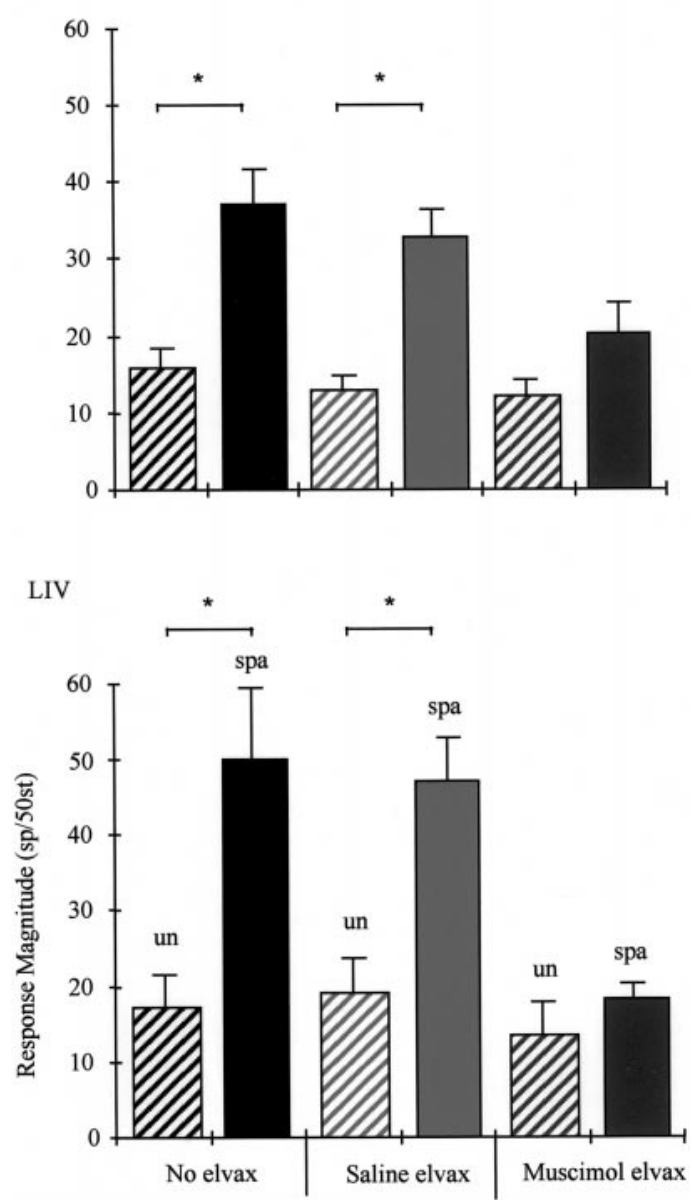

Figure 4. Potentiation of near-neighbor whisker responses. The group averages are shown for layer II/III cells (top) and layer IV cells (bottom). Spared whisker responses in undeprived animals (un) are compared with spared whisker responses in deprived animals $(s p a)$ for each condition, i.e., no elvax (left pair), saline-elvax (middle pair), and muscimol-elvax (right pair). Top, Layer II/III. In animals without any implants the average response is $\sim 15.5$ spikes per stimulus (black hatched bar, left). This measure is very similar in animals receiving saline-elvax (pale gray hatched bar, middle) or muscimol-elvax (dark gray hatched bar, right). After deprivation, the spared whisker responses increase by 2.3-fold in the near half of the neighboring barrel for animals with no elvax implant (solid black bar, left). The saline-elvax does not prevent potentiation (solid gray bar, middle). However, muscimol-doped elvax reduces the size of the increase in layer II/III to insignificant levels (dark gray bar, right; see Results). Bottom, Layer IV. The normal level of the near-neighbor response is on average 17.1 spikes per 50 stimuli. This measure is unchanged in undeprived animals receiving saline-elvax or muscimol-elvax. Chessboard pattern deprivation produces a 2.9 -fold potentiation of the near-neighbor response in the deprived barrel. Potentiation occurs normally in animals receiving saline-elvax (solid gray bar, middle), but muscimol blocks potentiation (dark gray bar, right). Asterisks indicate significant differences $(p<0.001)$.

In summary, potentiation and depression occurred normally in layers II/III or IV in animals with saline-elvax implants.

\section{The effect of muscimol treatment on sensory responses in undeprived animals}

Having established that the implant has no effect on its own on either normal responses or plasticity, we looked to see whether muscimol had an effect on baseline sensory responses in undeprived animals after the muscimol had "washed out."

\section{Near-neighbor responses}

In general, muscimol did not affect the magnitude of response to stimulation of near-neighboring whiskers (see Table 3) after it had stopped diffusing into the brain (see Appendix). Figure 4 shows the average response levels for stimulation of nearneighbor whiskers in layers II/III (top) and IV (bottom) that can be seen to be similar for undeprived cases. A two-way ANOVA showed that there was no difference between near-neighbor responses in animals with muscimol-elvax implants compared with animals with saline-elvax implants or animals without any implant at all either in layer II/III $\left[F_{(2,18)}=0.76 ; p=0.48\right]$ or layer IV $\left[F_{(2,17)}=0.46 ; p=0.64\right]$.

\section{Principal whisker responses}

Muscimol treatment tended to decrease principal whisker responses in undeprived animals. In layer II/III, the average principal vibrissa responses appeared to be $29 \%$ lower in muscimolelvax-treated animals at $32.5 \pm 1.9 \mathrm{sp} / 50 \mathrm{st}$ compared with $45.5 \pm$ $4.3 \mathrm{sp} / 50 \mathrm{st}$ in saline-elvax-treated animals, although these values were not significantly different $[U(7,7)=10 ; p>0.06]$. However, in layer IV, muscimol treatment did cause a significant $19 \%$ decrease in principal whisker response. We estimated the principal vibrissa response to be $47 \pm 3 \mathrm{sp} / 50 \mathrm{st}$ in undeprived animals after chronic muscimol treatment compared with $59 \pm 5.3 \mathrm{sp} / 50 \mathrm{st}$ in those with saline-elvax implants $[t(12)=2.9 ; p=0.013]$.

In summary, we find that for undeprived animals, muscimol treatment does not significantly alter surround receptive field responses or principal whisker responses in layer II/III but does reduce slightly principal whisker responses in layer IV.

\section{The effect of muscimol treatment on plasticity}

\section{The effect of muscimol on experience-dependent potentiation}

The effect of chessboard pattern deprivation on near-neighbor responses is shown in Figure 4 for all treatment groups. It can be seen that although potentiation occurs in animals with or without saline-elvax implants, muscimol treatment blocks potentiation. Because muscimol does not have a depressive effect on nearneighbor responses, we can determine the effect of muscimol on potentiation by comparison of the chessboard pattern deprivation animals with any of the undeprived treatment groups. However, for consistency we make the comparison with undeprived animals receiving muscimol-elvax implants.

In layer II/III, near-neighbor responses average $20 \pm 4.2 \mathrm{sp} /$ 50st compared with $12 \pm 2.35 \mathrm{sp} / 50 \mathrm{st}$ in undeprived animals with a muscimol implant. The responses in undeprived and deprived cases are not significantly different $[t(12)=1.66 ; p=0.122]$. Similarly, muscimol treatment prevented an increase in layer IV near-neighbor responses that remained at $18.4 \pm 1.8 \mathrm{sp} / 50 \mathrm{st}$ compared with $13.5 \pm 4.1 \mathrm{sp} / 50 \mathrm{st}$ in muscimol-treated undeprived animals $[t(12)=1.07 ; p=0.30]$.

For principal whisker responses in layer II/III, there was no significant difference in the average response magnitude of spared responses $(46.5 \pm 5.35 \mathrm{sp} / 50 \mathrm{st})$ compared with undeprived responses $(32.5 \pm 2 \mathrm{sp} / 50 \mathrm{st})$ in the presence of muscimol $[U(7,7)=$ $16 ; p=0.28$ ] (see Discussion). Similarly, for layer IV, the average response magnitude in spared barrels remained at control levels in the presence of muscimol with a value of $53.0 \pm 3.5 \mathrm{sp} / 50 \mathrm{st}$ compared with $47 \pm 3.0 \mathrm{sp} / 50 \mathrm{st}$ in undeprived animals (see Fig. $6)$. These values were not significantly different $[t(12)=1.51$; $p=0.16]$. 
Table 3. Near-neighbor responses of cortical layer II/III cells in chessboard-deprived and undeprived animals receiving muscimol treatment

\begin{tabular}{lllcc} 
Treatment & $\begin{array}{l}\text { Deprivation } \\
\text { condition }\end{array}$ & $\begin{array}{l}\text { Layer II/III } \\
\text { mean } \pm \\
\text { SEM }\end{array}$ & $\begin{array}{l}\text { Layer IV } \\
\text { mean } \pm \\
\text { SEM }\end{array}$ & $\begin{array}{l}\text { Number of } \\
\text { cases }\end{array}$ \\
\hline No implant & Undeprived & $15.5 \pm 2.45^{a}$ & $17.1 \pm 4.38$ & 7 \\
No implant & Spared & $36.5 \pm 4.7$ & $50 \pm 9.5$ & 11 \\
Saline-elvax & Undeprived & $13 \pm 1.95$ & $19.2 \pm 4.3$ & 7 \\
Saline-elvax & Spared & $32.5 \pm 3.5$ & $47 \pm 5.8$ & 6 \\
Muscimol-elvax & Undeprived & $12 \pm 2.35$ & $13.5 \pm 4.1$ & 7 \\
Muscimol-elvax & Spared & $20 \pm 4.2$ & $18.4 \pm 1.8$ & 7 \\
\hline
\end{tabular}

${ }^{a}$ Mean \pm SEM; sp/50st.

\section{The effect of muscimol on experience-dependent depression}

In previous studies, we found that chessboard pattern deprivation causes depression of deprived whisker responses in the principal barrel column. Furthermore, sparing neighboring whiskers increases depression of sensory responses to stimulation of a previously deprived principal whisker (Glazewski and Fox, 1996; Glazewski et al., 1998; Wallace and Fox, 1999a,b). These results imply that the presence of surround receptive field input, rather than just the absence of principal whisker input, can influence depression of principal whisker responses. We therefore looked at the effect of blocking cortical activity on depression.

In contrast to results in animals receiving saline-elvax implants, a period of chessboard deprivation in the presence of muscimol did not increase the percentage of unresponsive cells in deprived barrel columns in layer II/III or IV (Fig. 5). In layer II/III, unresponsive cells accounted for $17 \%$ of the total in muscimoltreated animals versus $12 \%$ in muscimol-treated undeprived animals. In contrast, the percent of unresponsive cells is $40 \%$ in saline-elvax-treated animals with whisker deprivation. Similarly, in layer IV, just $3 \%$ of the cells were unresponsive in deprived animals versus $1 \%$ in undeprived cases.

Because muscimol depresses the responses of the layer IV principal whisker when applied chronically to undeprived animals, we needed to ascertain the effect of muscimol treatment on plasticity in undeprived animals receiving a muscimol-elvax implant and in deprived animals receiving a muscimol implant. We found no difference between the distribution of responses to deprived principal whiskers and undeprived principal whiskers in muscimol-treated cortex, either for layers II/III $[t(11)=0.873$; $p=0.4]$ or IV $[t(12)=0.825 ; p=0.425]$.

If muscimol treatment were incapable of blocking depression, the depressive effect of muscimol would add to the depressive effect of deprivation. However, quite the opposite occurred. Not only does muscimol not add to the depression, but it prevents it. This can be seen after the muscimol-induced depression is subtracted out of the response and is illustrated in Figure 6. The average absolute responses are shown (Fig. 6, top) together with the responses corrected for the average response level in undeprived animals with similarly treated cortex (Fig. 6, bottom).

\section{Comparisons of spared and deprived responses}

As a further test of the effect of muscimol on plasticity, we looked at the difference between the spared and deprived principal vibrissa responses within each treatment group. This method has the advantage of providing a within-treatment control.

With reference to Figure 6, it can be seen that spared and deprived principal vibrissa responses are different in the groups without elvax and those treated with saline-elvax but are very similar in the muscimol-elvax-treated groups. In layer II/III, the average spared vibrissa response is $46.5 \pm 5.3 \mathrm{sp} / 50 \mathrm{st}$, whereas the deprived vibrissa response recorded in the same animals is $38 \pm$ $7.5 \mathrm{sp} / 50 \mathrm{st}$. These values are not significantly different $[t(10)=$ $1.2 ; p=0.23]$.

A similar effect occurs in layer IV, where the spared and deprived principal vibrissa responses are different when elvax has not been implanted or saline-elvax has been implanted but are practically identical when muscimol-elvax has been implanted. The average spared vibrissa response is $53.0 \pm 3.5 \mathrm{sp} / 50 \mathrm{st}$, and the average deprived vibrissa response is $53.2 \pm 7.6 \mathrm{sp} / 50 \mathrm{st}$; these values are clearly not statistically different $[t(12)=0.03 ; p=0.98]$.

\section{The effect of cortically applied muscimol on thalamic VPm responses}

A number of recent studies have found evidence of efferent projections from somatosensory cortex to subcortical structures affecting somatosensory responses in those nuclei. For example, in monkeys, chronic APV application to the cortical hand representation causes an increase in receptive field size in the corresponding thalamic nucleus VPl (Ergenzinger et al., 1998). To see whether muscimol treatment of the barrel field had a similar effect on the thalamic nucleus responsible for the whisker pad, VPm, we recorded receptive field size and the magnitude of the center and surround receptive field response in thalamus while applying muscimol to the corresponding cortical projection site.

\section{Acute application of muscimol}

In these experiments we were able to map responses in the same area of VPm before and after cortical muscimol application (before, 55 cells; after, 36 cells; four animals). Muscimol was applied to the surface at a concentration of 100 or $200 \mu \mathrm{M}$, and its effect on cortical responses was monitored by recording evoked potentials. The average center receptive field (CRF) response was $59.3 \pm 4.22 \mathrm{sp} / 50 \mathrm{st}$ before muscimol application. This value is almost identical to values reported previously from our (Glazewski et al., 1998; Wallace and Fox, 1999a) and other laboratories (Armstrong-James and Callahan, 1991) for a rapid $1^{\circ}$ whisker deflection. Muscimol application abolished cortical responses to a depth of $1.5 \mathrm{~mm}$ after $\sim 2 \mathrm{hr}$ for a surface concentration of 200 $\mu \mathrm{M}$. At this point we mapped VPm again and found average CRF responses to be effectively unchanged at $67 \pm 5.4 \mathrm{sp} / 50 \mathrm{st}[t(5)=$ $5 ; p>0.5]$.

We also estimated receptive field size for the same neurons by testing all whiskers immediately surrounding the CRF whisker. Considering just those whiskers generating responses of at least 
LII/III Muscimol elvax undeprived

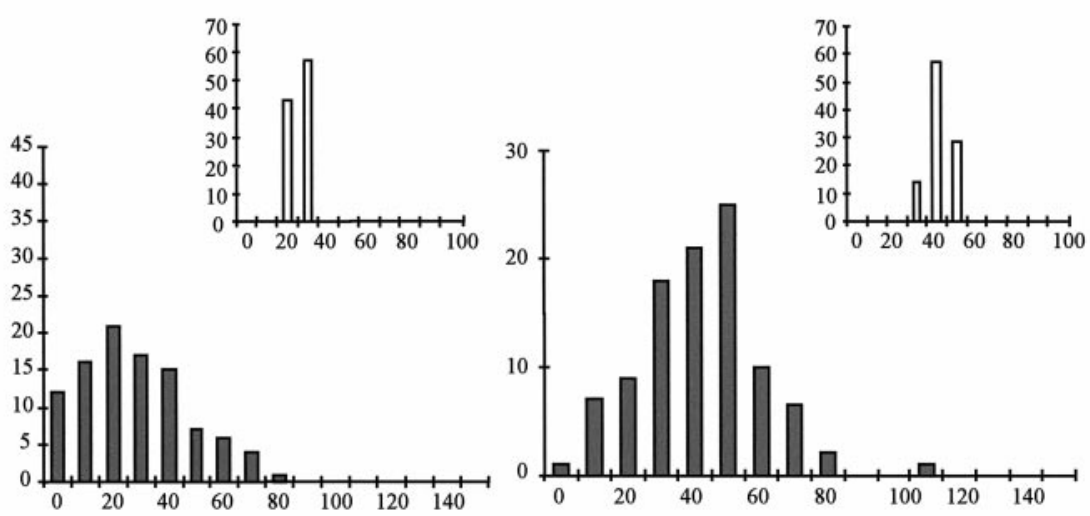

Figure 5. The effect of muscimol on principal whisker responses. The response magnitude distributions for deprived (regrown) whiskers are shown for cells in layer II/III (left $)$ and layer IV (right). Top, In layer II/III, muscimol does not affect undeprived principal whisker responses compared with control (see Fig. 3, Saline-elvax undeprived). On average, responses are decreased slightly in layer IV. Middle, Bottom, Muscimol prevents the decrease of principal whisker responses (middle) caused by deprivation (bottom) and indicated by a leftward shift in the distribution. The insets are the distribution of average response levels for each individual animal. Conventions are described in Figure 3.

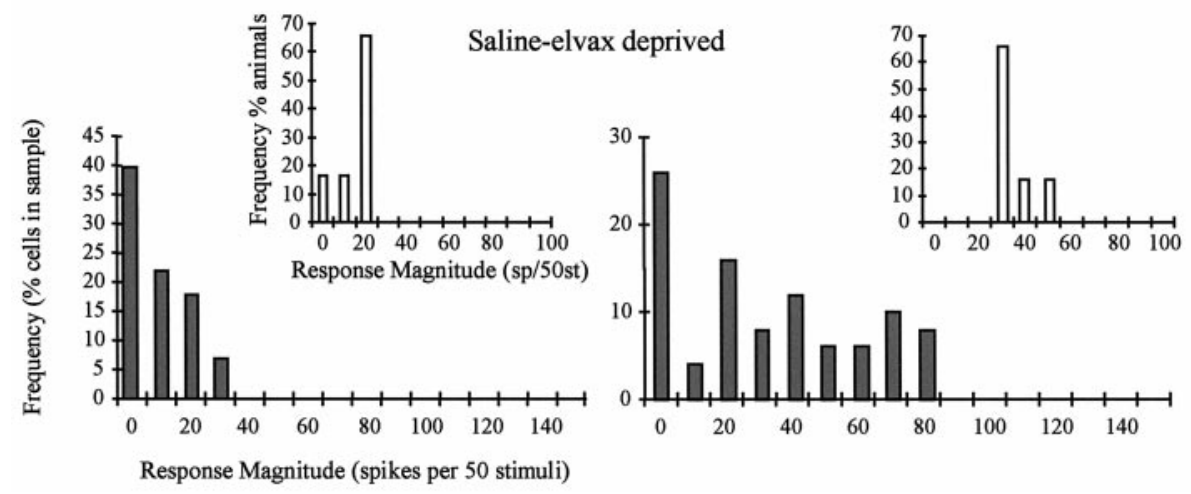

0.5 spikes/stimulus, an average of 1.66 and 1.45 whiskers composed the receptive field before and after, respectively, cortical application of muscimol. The distributions of receptive field sizes are not different as can be seen in Figure 7. Finally, we measured the responses to the SRF whiskers and found the magnitude of response not to be different before $(10.0 \pm 2.2 \mathrm{sp} / 50 \mathrm{st})$ and after $(10.9 \pm 2.8 \mathrm{sp} / 50 \mathrm{st})$ acute muscimol application $[t(52)=0.26 ; p>$ 0.79]. These results do not support the hypothesis that acutely blocking cortical activity enlarges surround receptive fields in rat VPm.

\section{Chronic application of muscimol}

It seemed possible that the continuous application of muscimol over a longer time period might provoke changes not seen with acute muscimol application over a period of hours. Therefore, we implanted muscimol-elvax in 10 animals and looked at cortical and VPm response levels 2, 4, and $7 \mathrm{~d}$ after implantation. We first mapped the edge of the responsive area in the cortex to determine the barrels affected by muscimol and therefore the principal whisker responses likely to be affected in VPm.

Two days after implantation, the muscimol block still extended $\sim 1 \mathrm{~mm}$ from the edge of the elvax and the entire depth of the cortex below the elvax. With the elvax still in place, CRF responses in VPm appeared to be $36 \%$ greater than control at $76.5 \pm 15.7 \mathrm{sp} / 50 \mathrm{st}$ (39 cells; three cases), but this was not significantly different from control $[t(5)=1.22 ; p>0.38]$. Similarly, the SRF responses were not elevated at $13.2 \pm 2.3 \mathrm{sp} / 50 \mathrm{st}$ $[t(71)=0.97 ; p>0.33]$.

By $4 \mathrm{~d}$, the cortical block was still present although over a smaller area of cortex than at $2 \mathrm{~d}$. The center receptive field responses of whiskers the barrels of which were blocked in cortex 

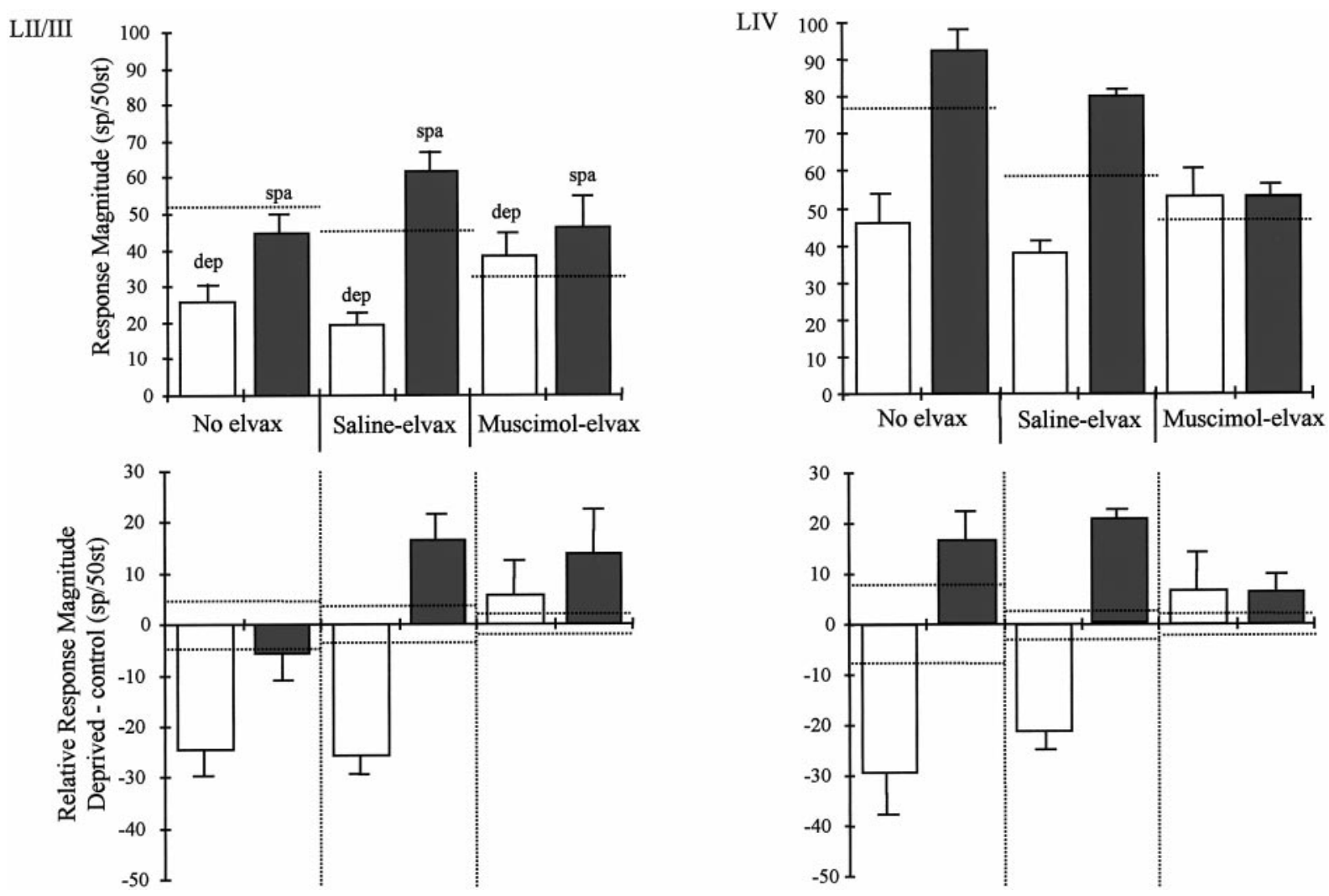

Figure 6. Comparison of saline-elvax and muscimol-elvax treatment on potentiation and depression. Average responses are shown in the top row of histograms for average principal whisker responses of layer II/III (left) and layer IV (right). Top left, Deprived whisker responses (dep, white bars) are significantly lower than spared whisker responses (spa, gray bars) in animals without elvax implants (no elvax, left). Similarly, deprived and spared whisker responses are different in animals receiving saline-elvax implants (middle). However, in animals receiving muscimol-elvax implants, spared and deprived whisker responses recorded in the same animals are similar and not significantly different (right). Top right, The same result is found in layer IV where spared and deprived responses are different in each case except for that in which the cortex is treated with muscimol. Dashed horizontal lines indicate average responses in undeprived animals. Bottom left, Relative responses of layer II/III cells are shown. The same data shown in the top row are replotted, having subtracted out the average undeprived whisker responses of the respective treatment groups. In animals without implants, principal whiskers responses are depressed in deprived barrel columns and are not significantly changed in spared layer II/III barrel columns. In animals with saline-elvax implants, depression occurs in deprived barrel columns, and a degree of spared whisker potentiation occurs in spared barrel columns. However, in animals treated with muscimol, there is no depression and an insignificant level of potentiation. Bottom right, A similar result occurs in layer IV where deprived whisker responses are depressed (white bars) and spared whisker responses are potentiated ( gray bars). However, there is no significant change in animals treated with muscimol during deprivation. Horizontal dotted lines in the bottom panels represent SEs for the undeprived distributions (which have means adjusted to zero for each treatment group).

were still at control levels $(60.3 \pm 12.1 \mathrm{sp} / 50 \mathrm{st}$; four cases $)$, but the SRF responses were elevated by $78 \%$ at $18 \mathrm{sp} / 50 \mathrm{st}[t(57)=2.31$; $p<0.025]$. At this stage, the number of whiskers contributing to the SRF was also increased to an average of 2.87 whiskers. As shown in Figure 7, the distribution of receptive field sizes is shifted right after $4 \mathrm{~d}$ of chronic muscimol treatment.

At $7 \mathrm{~d}$, the muscimol block was present in cortex but mainly within $250 \mu \mathrm{m}$ of the elvax. Furthermore, the muscimol block did not extend down as far as the layer V and VI cells that project to the thalamus. Under these conditions we found that CRF responses were normal at $59.7 \pm 4.9 \mathrm{sp} / 50 \mathrm{st}$ (three cases) as were the SRF responses at $7.8 \pm 2.0 \mathrm{sp} / 50 \mathrm{st}[t(54)=0.83 ; p>0.4]$. The size of the surround receptive fields was also indistinguishable from control levels at an average value of 1.36 whiskers. As shown in Figure 7, the distribution of receptive field sizes was very similar $7 \mathrm{~d}$ after implantation compared with control.

The results suggest that chronic application of muscimol increases SRF responsivity in VPm after $4 \mathrm{~d}$ of treatment but that it returns to control values when the effect of muscimol treatment wanes at $\sim 7 \mathrm{~d}$ after implantation.

\section{DISCUSSION}

The present findings demonstrate that cortical activity is required for experience-dependent potentiation and depression of sensory responses in the barrel cortex. The results support the conclusions of previous studies that plasticity occurs as a result of activitydependent mechanisms in the cortex (Fox, 1994; Glazewski et al., 1998; Wallace and Fox, 1999b) but provide a direct test of this hypothesis. Previous studies had shown that whisker deprivation does not lead to plasticity in VPm (Glazewski et al., 1998; Wallace and Fox, 1999a) but does lead to plasticity in the cortex (Fox, 1994), strongly suggesting a cortical origin for plasticity. The present results confirm and extend these ideas, by showing that blocking cortical activity is sufficient to prevent cortical plasticity. Furthermore, a block of cortical activity affects both components of plasticity, potentiation and depression.

\section{Depression of sensory responses}

In theory, depression of cortical responses might arise in one of two ways. Either inactivity at one or several synapses leads to passive decay of synaptic strength, or activity leads to weakening 

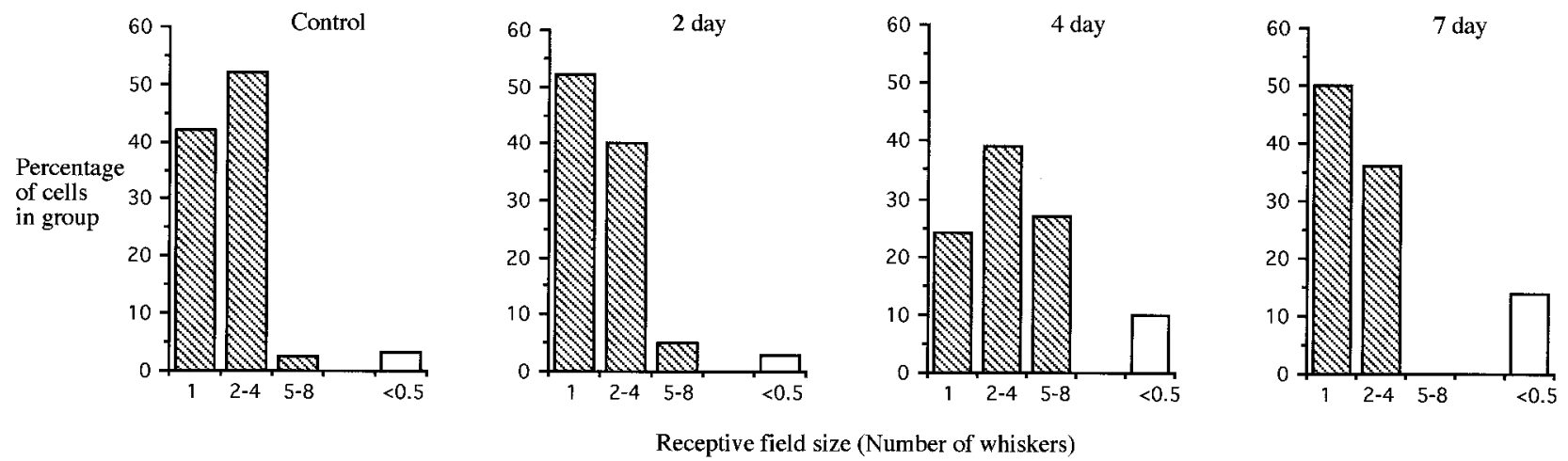

Receptive field size (Number of whiskers)
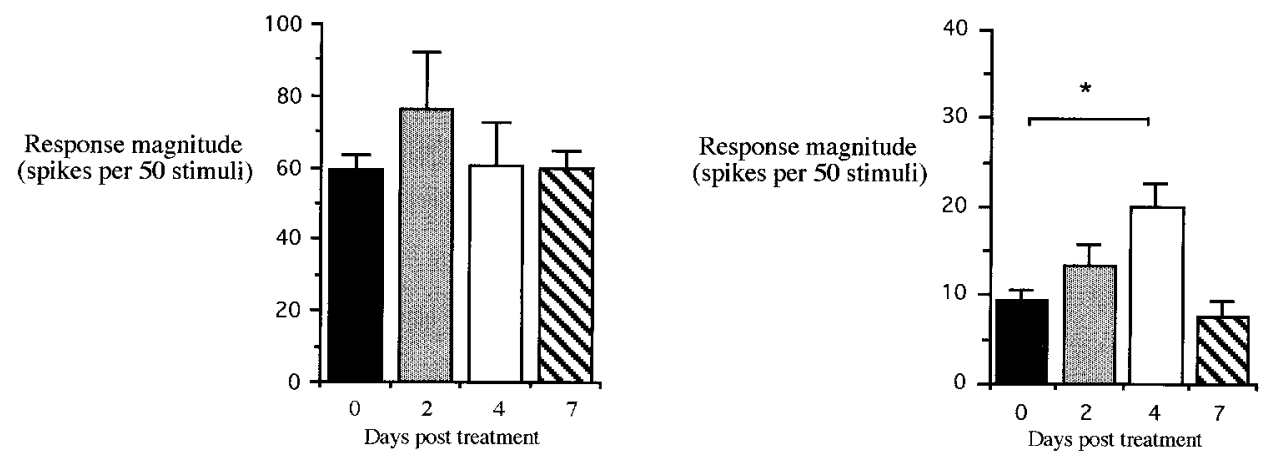

Figure 7. The effect of cortical muscimol treatment on VPm responses. Top row, The number of whiskers comprising the receptive field for VPm cells at different periods after the start of cortical muscimol treatment [from left to right, $0 \mathrm{~d}$ (i.e., control), $2 \mathrm{~d}, 4 \mathrm{~d}$, and $7 \mathrm{~d}$ )]. Only whiskers eliciting responses $\geq 25$ spikes per 50 stimuli are included in this analysis. The number of whisker responses falling outside this range is shown on the right of each histogram (white bar, <0.5). Note that the distribution shifts right, indicating an increase in receptive field size, after $4 \mathrm{~d}$ but returns to normal at $7 \mathrm{~d}$. Bottom row, left, Responses of VPm cells to stimulation of center receptive field whiskers at various stages after starting cortical muscimol treatment (black bar, $0 \mathrm{~d}$; gray bar, $2 \mathrm{~d}$; white bar, $4 \mathrm{~d}$; hatched bar, $7 \mathrm{~d}$ ). Note that responses are similar during treatment. Bottom row, right, Response magnitude of V Pm neurons to stimulation of surround receptive field whiskers. Note that at $4 \mathrm{~d}$ there is an increase in response, which falls back to normal at $7 \mathrm{~d}$. The asterisk denotes significance at $p<0.025$.

of synaptic strength at a set of inactive or active but uncorrelated synapses. Muscimol treatment distinguishes between the two alternatives because it affects each mechanism differently. For the passive decay mechanism, the inactivity caused by muscimol treatment would itself cause decay of synaptic strength. However, this was not the result found; muscimol treatment in the absence of deprivation did not alter cortical responses in layer II/III or surround receptive field responses in any layer. Although some principal whisker depression occurred in layer IV, these synapses were not strictly inactive because the presynaptic thalamocortical inputs were still present. This only leaves the other alternative as a possibility, that synaptic depression requires activity to weaken synapses. Muscimol treatment would be expected to prevent depression in this case, and indeed this was the result found.

\section{Potentiation of cortical responses}

Chessboard pattern deprivation also produces potentiation of spared whisker responses on the near side of the deprived neighboring barrel column (Wallace and Fox. 1999a). Plasticity occurs much more rapidly when several whiskers are spared compared with the situation when a single whisker is spared (Wallace and Fox, 1999b), and one possible reason for this is that when several whiskers are present there is an opportunity for summation of responses produced by coincident whisker stimulation (Armstrong-James et al., 1994; Wallace and Fox, 1999b). Because chessboard pattern deprivation does not cause plasticity in VPm (Wallace and Fox, 1999a), the cooperative interaction between whisker responses is likely to take place in the cortex. The fact that expression of plasticity relies on pathways between barrels further supports this idea (Fox, 1994). The present results demonstrate that cortical activity is required for cortical potentiation and together with the results cited above imply that this activity is required for potentiation of pathways between cortical barrel columns.

Potentiation also occurs within the spared column in layer II/III (this study) (Barth et al., 2000), although it is occasionally difficult to detect from the average responses calculated for each animal (see Barth et al., 2000). Although animals implanted with saline-elvax showed potentiation, animals without implants did not (Fig. 6). A previous study also failed to show principal whisker plasticity in layers II/III within the spared column [Rema et al. (1998), their Fig. 11], although its presence had been reported in an earlier study by the same group [Armstrong-James et al. (1994), their Fig. 4]. It is therefore difficult to draw any firm conclusions about the apparent block of principal whisker plasticity in layers II/III within the spared column by muscimol at present. In contrast, surround receptive field plasticity is clearly present in layers II/III and is clearly blocked by muscimol.

Previous studies have shown that infusion of APV into the CSF 
is also capable of preventing potentiation caused by sparing two whiskers (Rema et al., 1998). The small degree of plasticity in layer IV of the spared column (an increase from $\sim 25$ to 31 sp/50st) was prevented by APV treatment (Rema et al., 1998). In that study, plasticity was only examined in the spared barrels. The present results show that potentiation also occurs in deprived barrels and that this also requires cortical activity.

In the present study, muscimol clearly acted by blocking activity. In contrast, it is not clear whether APV acts in vivo by decreasing activity or by a more specific mechanism, such as preventing calcium entry via NMDA receptors. On the one hand, it is known that NMDA receptors comprise a significant component of the excitatory response in supragranular layers (Fox et al., 1989; Armstrong-James et al., 1993). Consequently, chronic application of $500 \mu \mathrm{M}$ APV led to a $90-100 \%$ decrease of layer II principal whisker responses and 60-100\% suppression of layer III principal whisker responses (Rema et al., 1998). This suggests that a decrease in activity cannot be excluded. On the other hand, it is known that whisker deprivation plasticity in barrel cortex is dependent on calcium-calmodulin kinase type II and that this kinase requires activation by calcium from some source (Glazewski et al., 1996, 2000). Calcium may enter through NMDA receptors; however, it may enter through voltage-gated calcium channels or be released from intracellular stores via metabotropic glutamate receptor activation. Further studies will be required to distinguish between these alternatives.

\section{The effect of cortical block on VPm responses}

It has been noted in the literature that blocking cortical activity can have an effect on thalamic inputs projecting to that cortical area, presumably via back-projections from the cortex to the thalamus. Whether inactivation of somatosensory cortex has no effect on VPm (Diamond et al., 1992; Rema et al., 1998; Parker and Dostrovsky, 1999), a facilitatory effect (Ergenzinger et al., 1998), or a mixed effect (Krupa et al., 1999; see Fox et al., 2000) has yet to be resolved. In agreement with other studies on rat cortex (Diamond et al., 1992), we found that acute inactivation had no effect on thalamic VPm responses to whisker stimulation.

However, $4 \mathrm{~d}$ of muscimol treatment produced a small but significant facilitatory effect on receptive field size. Because the facilitatory effect was not sustained beyond $4 \mathrm{~d}$, the measurements made in the cortex after deprivation at $14 \mathrm{~d}$ were equivalent for cases in which muscimol had or had not been applied. VPm receptive fields were also identical at $2 \mathrm{~d}$, suggesting that the effect could only have been present from the third to sixth day at most. Expanding the receptive fields slightly for a short duration during deprivation should, if anything, have led to even greater plasticity than normal, but instead plasticity was blocked in these animals, which implies that the degree of cortical inactivation was sufficient to overcome any thalamic effect.

\section{Mechanisms of cortical plasticity}

One of the unexpected aspects of this study was the finding that plasticity is blocked so effectively when only the first few days of deprivation were influenced by muscimol treatment. Recent studies have shown that changes in cortical organization occur rapidly after commencing deprivation. Changes in early gene expression (Barth et al., 2000) and layer II/III transmission properties (Diamond et al., 1994; Barth et al., 2000) can be detected 16 hr after starting deprivation. The trigger for these initial changes is likely to be changes in phasic inhibition brought about by the deprivation (Kelly et al., 1999; see Fox et al., 2000). The initial stages of plasticity probably trigger a set of actions in the cortex, including gene expression, that once set in motion cannot stop and result in plasticity expression several days later.

It is possible that plasticity recovers somewhat during the period between the end of the direct muscimol effect at $\sim 4-7 \mathrm{~d}$ and the period when the whiskers start to regrow at 7-10 d. It is not obvious that this is the case because responses in undeprived animals were the same as those in deprived animals receiving muscimol treatment. However, if reverse plasticity had occurred in the barrel cortex, as it does in visual cortex treated with muscimol (Reiter and Stryker, 1988; Hata and Stryker, 1994; Hata et al., 1999), so that the deprived whisker inputs had actually been potentiated rather than depressed during muscimol treatment, then the period of recovery may have brought the deprived whisker responses back down to control levels again. Further experiments will be required to resolve this issue.

Recent results in barrel cortex in vitro have emphasized the importance of the interval between presynaptic and postsynaptic action potentials in determining whether synapses weaken or strengthen (Markram et al., 1997; Egger et al., 1999; Feldman, 2000). In the layer IV to II/III pathway, if presynaptic action potentials arrive $10-20 \mathrm{msec}$ before the postsynaptic spike occurs, it produces long-term potentiation, whereas if the presynaptic input arrives after the postsynaptic spike by up to $100 \mathrm{msec}$, it causes long-term depression (Feldman, 2000). On average, random spikes in the deprived presynaptic pathway would cause depression rather than potentiation because the time window for depression is longer than that for potentiation (Feldman, 2000; see Fox, 2000). This would suggest a mechanism by which depression occurs in chessboard-deprived animals when spontaneous presynaptic activity in the deprived whisker pathway randomly coincides with depolarization of the neuron caused by spared surround receptive field input.

In conclusion, we have shown that cortical activity is vital for experience-dependent plasticity in the cortex. Both potentiation and depression are dependent on activity. This implies that passive decay of synaptic gain because of inactivity does not occur in the cortex and that timing-based rules of synaptic plasticity are plausible models for explaining experience-dependent plasticity in this system.

\section{APPENDIX \\ The effect of acute muscimol application on neuronal activity}

Iontophoretic application of muscimol at the recording site (51 cells) or topical application of muscimol to the surface of the brain (47 cells) produced qualitatively similar effects on neuronal activity. The first sign of a muscimol effect was signaled by a decrease in spontaneous activity. A progressive loss of response to whiskers comprising the surround receptive field followed. Muscimol then affected the center receptive field, initially by reducing the later components of the response until the poststimulus time histogram consisted of just a single 1-2 msec time bin. Finally, the response to center receptive field stimulation at the remaining latency decreased until it became undetectable. We often observed that a background "hash" of short latency-evoked activity remained, even after several hours of muscimol treatment, that did not become spontaneously active or alter sensory response when glutamate was applied iontophoretically (six animals; 29 locations); we therefore concluded that this residue was presynaptic (thalamocortical) in origin. 
A
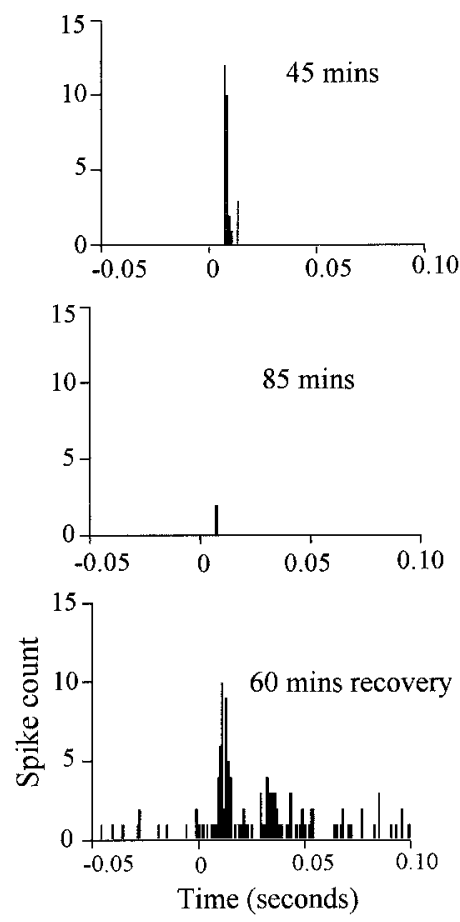

B
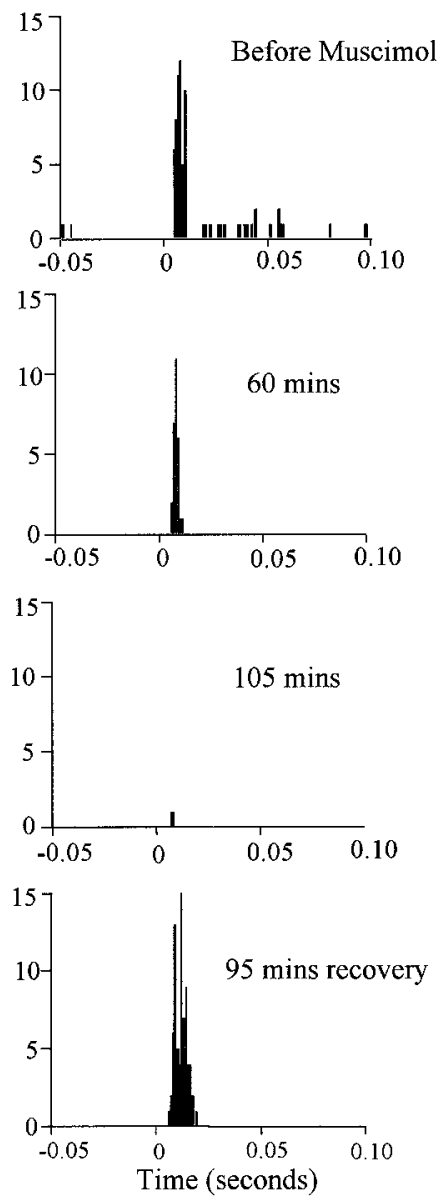

C

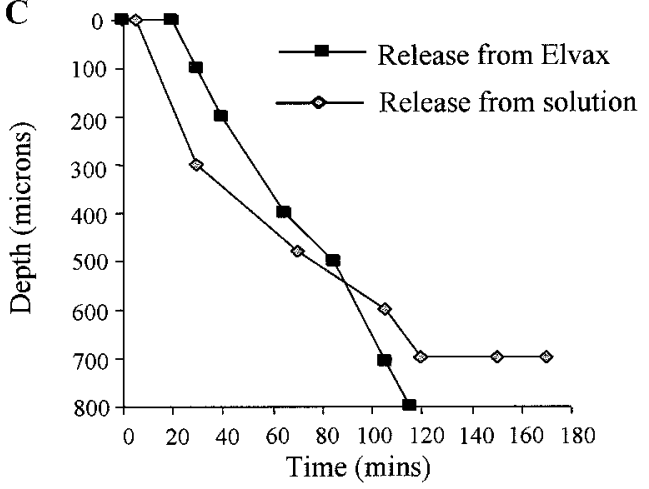

D

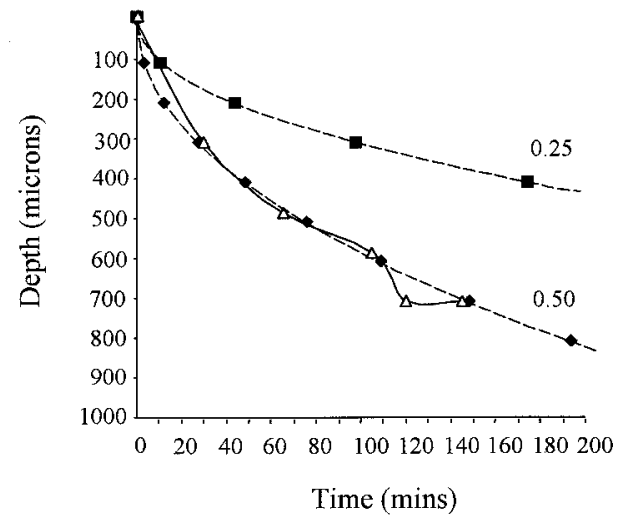

Figure 8. Diff usion of muscimol within the cortex. Neuronal spike activity gives an index of the presence of muscimol. Sensory responses were measured before, during, and after application of muscimol to the cortical surface. A, PSTHs for principal whisker stimulation show that muscimol released from muscimol-doped elvax causes the cell to lose its response after $85 \mathrm{~min}$. After removal of the elvax the response returns within $1 \mathrm{hr}(\mathrm{cell}$ depth $=500 \mu \mathrm{m})$. $B$, Muscimol applied to the cortex at a concentration of $100 \mu \mathrm{M}$ causes a loss of response after 105 min. Recovery of the response occurs after 95 min of washing the surface clear of muscimol (cell depth $=700 \mu \mathrm{m}$ ). $C$, The time at which muscimol blocks the response of the cells is plotted against the depth of the cells for application of muscimol via elvax (black squares) and topical application in isotonic saline at $100 \mu \mathrm{M}$ muscimol (gray diamonds). $D$, Topical application of muscimol fits the theoretical curve for diff usion of muscimol from a constant concentration source of $100 \mu \mathrm{M}$. Theoretical curves are shown for the point at which the concentration reaches one-quarter $(0.25)$ and one-half ( 0.5$)$ of the surface concentration. Clearly, the experimentally derived curve ( gray triangles, solid line) corresponds most closely to the 0.5 theoretical curve (black diamonds, dashed line), indicating that muscimol blocks principal whisker responses at $\sim 50 \mu \mathrm{M}$ (i.e., $0.5 \times 100 \mu \mathrm{M}$ ). Note in $C$ that when muscimol is released from elvax, diffusion is initially slower than that from a constant $100 \mu \mathrm{M}$ source but after $\sim 80 \mathrm{~min}$ becomes faster.

\section{Diffusion of muscimol in the brain}

We tracked the ventral diffusion of muscimol from the surface of the cortex into the cortex by observing its effect on neuronal responses to stimulation of the principal whisker (six animals). A neuron located within 1-200 $\mu \mathrm{m}$ of the cortical surface responded to principal whisker stimulation immediately after topical application of muscimol but decreased its response to sensory stimulation shortly thereafter. Subsequently, the response became undetectable, at which point we moved the electrode to the closest site that did show a response to principal whisker stimulation and waited again until the response became undetectable. By noting the time at which muscimol extinguished the response at each depth, we constructed a profile of the muscimol diffusion front as it advanced into the cortex (Fig. 8).

We estimated the rate of muscimol diff usion from a well of 100 $\mu \mathrm{M}$ muscimol applied directly to the cortical surface. We found that the rate of diffusion measured experimentally matched closely the theoretical rate. With the diff usion coefficient modified by reasonable values for tortuosity and volume fraction [measured previously by Nicholson and Phillips (1981)], muscimol entirely abolished responses at a concentration of $\sim 50 \mu \mathrm{M}$ (see Materials and Methods).

Muscimol diff used in a slightly more complex manner from the elvax than from the solution. The increase in concentration at various cortical depths is initially slower than that produced by a $100 \mu \mathrm{M}$ jump in concentration at the surface (Fig. 8). However, the concentration subsequently increases more rapidly after $\sim 1$ hr. We attribute the delay (of $\sim 30 \mathrm{~min}$ ) before the muscimol reaches an effective concentration to the time it takes water to diffuse into the elvax before the drug is dissolved and able to 


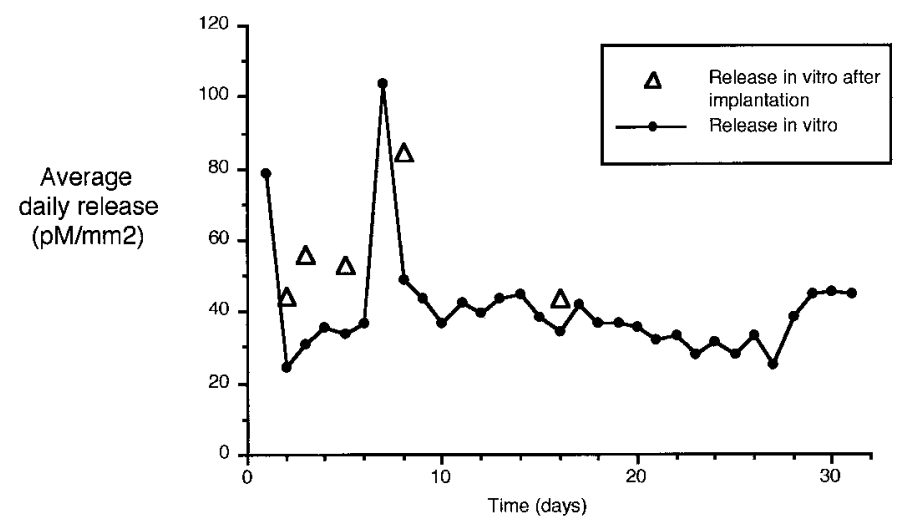

Figure 9. Release of muscimol from elvax in vitro estimated by measuring tritiated muscimol. Average release over $24 \mathrm{hr}$ at room temperature is shown for four cases followed over $30 \mathrm{~d}$ (black circles). Daily release varies between $\sim 30$ and $110 \mathrm{pm} / \mathrm{mm}^{2}$ over this period and shows no sign of ending at $30 \mathrm{~d}$. The rate of release is also shown for five pieces of elvax removed from a position over the cortex after 2, 3, 5, 8, and $16 \mathrm{~d}$ of dwelling in vivo (white triangles). The release in vitro over the succeeding $24 \mathrm{hr}$ is shown and is comparable with release from elvax maintained in vitro for the same period.

diffuse out. We attribute the faster rise in concentration that occurs after approximately 1 hour to the surface concentration increasing beyond $100 \mu \mathrm{M}$.

\section{Spatiotemporal characteristics of muscimol release from elvax}

We estimated the duration of muscimol release from elvax using tritiated muscimol (four triplicated cases). Muscimol-doped elvax releases at an average daily rate of $\sim 50-80 \mathrm{pM} / \mathrm{mm}^{2}$. The release rate continued without decline for several weeks in vitro (Fig. 9, black circles). Pieces of elvax that had been implanted in the brain for a number of days showed similar levels of release compared with elvax that had subsisted in vitro for the same length of time (Fig. 9, white triangles). This shows that the elvax still has the ability to release at the same rate after a period in vivo. However, muscimol-doped elvax applied to the brain only caused a decrease in neuronal activity for a period of just $>4 \mathrm{~d}$ (Fig. 10). The shorter period of action cannot be caused by exhausting the supply of muscimol in the elvax and is likely to be attributable to a barrier forming between the muscimol and the cortex possibly involving astrocytes, glia, or a thickening of the pial membrane.

During the first $2 \mathrm{~d}$ after implantation, muscimol inactivated sensory responses within a (tangential) distance of $\sim 0.8 \mathrm{~mm}$ from the edge of the implant (four cases studied) (Fig. 10). A typical piece of triangular elvax with an apical dimension of $2 \mathrm{~mm}$ and a base of $1 \mathrm{~mm}$ therefore inactivated an area of $\sim 4.7 \mathrm{~mm}^{2}$. We often implanted two pieces of elvax and made all recordings within $0.8 \mathrm{~mm}$ of the edge of the elvax in this study. For comparison, the area of the posterior medial barrel subfield covers an area of $\sim 7.5 \mathrm{~mm}^{2}$. The area affected decreased to $\sim 1.7 \mathrm{~mm}^{2}$ after $4 \mathrm{~d}$ (four cases) and only comprised the area immediately under the elvax to a depth of $\sim 250 \mu \mathrm{m}$ at $8 \mathrm{~d}$ (three cases studied). Muscimol did not appear to be present at 13-15 d after implantation because spontaneous activity was normal at this time point, and yet this is the property most sensitive to muscimol treatment (Fig. 10). Furthermore, we encountered neurons with surround receptive fields at a normal frequency at 13-15 d after implantation that would not have been the case had muscimol been present to suppress the surround receptive fields. Finally,
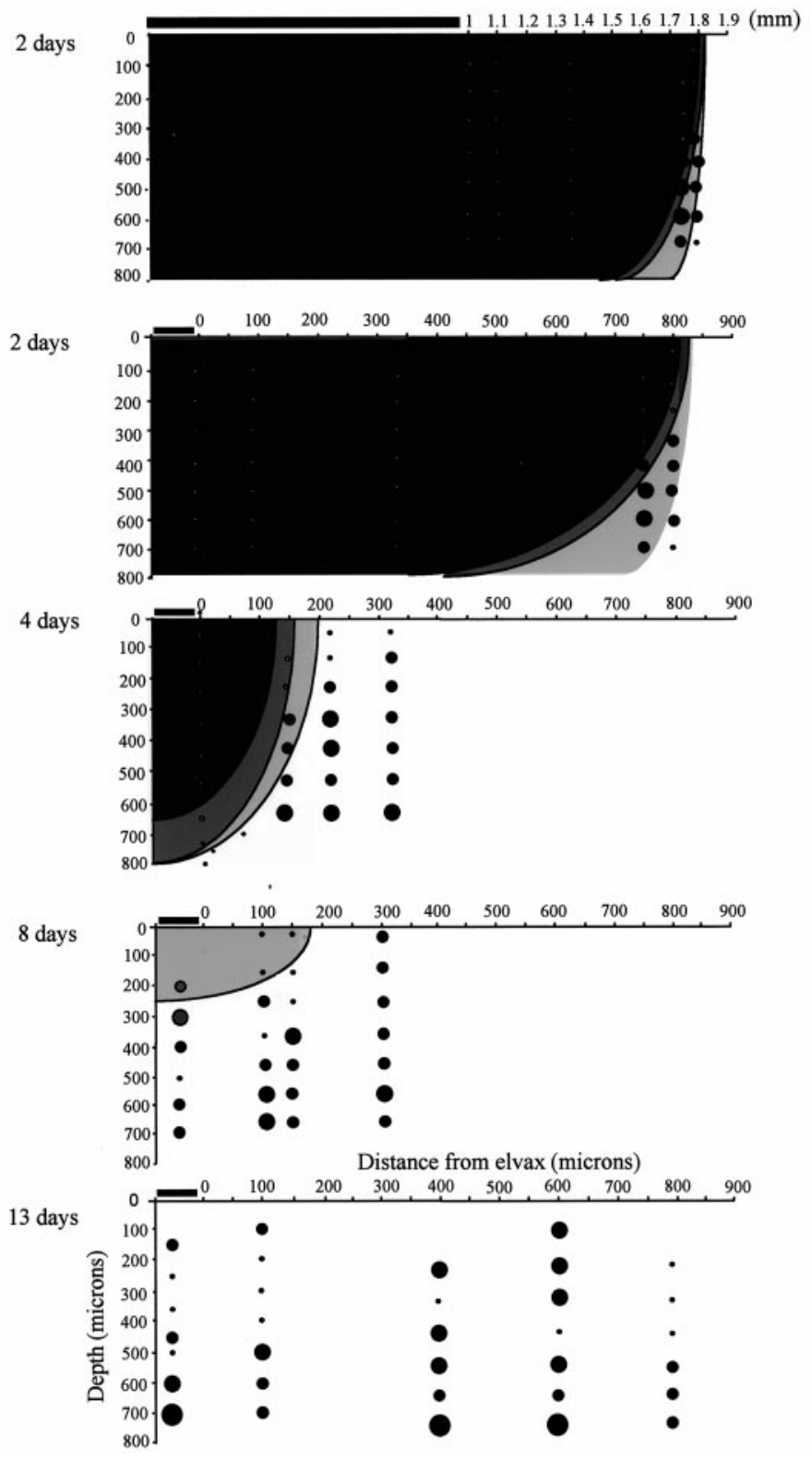

Figure 10. Release of muscimol from elvax into the cortex. Coronal cross sections through the cortex are shown for different animals in which cortical activity is evaluated at 2, 4, 8, and $13 \mathrm{~d}$ after elvax implantation. Top, Two days, The elvax spans $\sim 1 \mathrm{~mm}$ (horizontal bar). The effect of the muscimol extends $\sim 800 \mu \mathrm{m}$ from the edge of the elvax and at least to a depth of $700 \mu \mathrm{m}$. Bottom, Two days, A close-up of the edge of the elvax shows the location of several penetrations in which no spike activity was found and no responses could be elicited (white circles, dark gray shading). At the edge of the affected area, responses are found at $400 \mu \mathrm{m}$ (black circles, light gray shading). The size of the circles indicates the number of whiskers in the receptive field (smallest black circles, principal whisker response only; largest circle, 3 whiskers). Four days, The blocked area has shrunk to within $200 \mu \mathrm{m}$ of the edge of the elvax. Eight days, The area underneath the elvax responds at this time point below a depth of $\sim 300$ $\mu \mathrm{m}$ although responses were not at normal levels. Thirteen days, The direct action of muscimol is not detectable at $13 \mathrm{~d}$. Neurons have recovered their receptive fields, and spontaneous activity is present at normal levels. Dark gray shading, No spontaneous activity and no responses; gray shading, reduced responses; white background, normal responses. Open circles, No spontaneous activity and no responses; black circles, spontaneous activity but no responses; larger black circle, single whisker receptive field; intermediate-size black circle, principal whisker and a single surround receptive field whisker generating responses; largest circle, two or more surround receptive field whiskers generating responses. 
the duration of the PSTHs for principal whisker stimulation was also normal at 13-15 d, again indicating that muscimol had diffused out of the cortex. We therefore implanted muscimoldoped elvax at the same time that we deprived the whiskers and did not remove the elvax, even during the final recording session in most cases. On a few occasions, the elvax was moved to gain better access to the barrel field. In these cases, the results were identical to those in which the elvax was left in loco (four cases).

Figure 2 shows the timing of muscimol-doped elvax implantation relative to the whisker deprivation and regrowth period. Note that muscimol is active during the deprivation period but not during most of the regrowth period.

\section{REFERENCES}

Armstrong-James M, Callahan CA (1991) Thalamo-cortical processing of vibrissal information in the rat. II. Spatiotemporal convergence in the thalamic ventroposterior medial nucleus (VPm) and its relevance to generation of receptive fields of S1 cortical "barrel" neurones. J Comp Neurol 303:211-224.

Armstrong-James M, Fox K (1987) Spatiotemporal convergence and divergence in rat SI "barrel" cortex. J Comp Neurol 263:265-281.

Armstrong-James M, Fox K, Millar J (1980) A method for etching the tips of carbon fibre microelectrodes. J Neurosci Methods 2:431-432.

Armstrong-James M, Welker E, Callahan CA (1993) The contribution of NMDA and non-NMDA receptors to fast and slow transmission of sensory information in the rat SI barrel cortex. J Neurosci 13:2149-2160.

Armstrong-James M, Diamond ME, Ebner FF (1994) An innocuous bias in whisker use in adult rats modifies receptive fields of barrel cortex. J Neurosci 14:6978-6991.

Barth AL, Glazewski S, McKenna M, Hill P, Impey S, Storm D, Fox K (2000) Upregulation of CRE-mediated gene expression during experience-dependent plasticity in adult neocortex. J Neurosci 20:4206-4216.

Diamond ME, Armstrong-James M, Budway MJ, Ebner FF (1992) Somatic sensory responses in the rostral sector of the posterior group $(\mathrm{POm})$ and in the ventral posterior medial nucleus (VPM) of the rat thalamus: dependence on the barrel field cortex. J Comp Neurol 319:66-84

Diamond ME, Armstrong-James M, Ebner FF (1993) Experiencedependent plasticity in adult rat barrel cortex. Proc Natl Acad Sci USA 90:2082-2086.

Diamond ME, Huang W, Ebner FF (1994) Laminar comparison of somatosensory cortical plasticity. Science 265:1885-1888.

Egger V, Feldmeyer D, Sakman B (1999) Coincidence detection and changes of synaptic efficacy in spiny stellate neurons in rat barrel cortex. Nat Neurosci 2:1098-1105.

Ergenzinger ER, Glasier MM, Hahm JO, Pons TP (1998) Cortically induced thalamic plasticity in the primate somatosensory system. Nat Neurosci 1:226-229.

Feldman DE (2000) Timing-based LTP and LTD at vertical inputs to layer II/III pyramidal cells in rat barrel cortex. Neuron 27:45-56.

Finnerty GT, Llandudno SE, Roberts LS, Connors BW (1999) Sensory experience modifies the short term dynamic of neocortical synapses. Nature 400:367-371.

Fox K (1992) A critical period for experience dependent plasticity in somatosensory cortex. J Neurosci 12:1826-1838.

Fox K (1994) The cortical component of experience-dependent synaptic plasticity in the barrel cortex. J Neurosci 14:7665-7679.

Fox K (2000) Timing is everything. Neuron 27:1-3.

Fox K, Armstrong-James M (1986) The role of the anterior intralaminar nuclei and $N$-methyl-D-aspartate receptors in the generation of spontaneous bursts in rat cortical neurones. Exp Brain Res 63:505-518.

Fox K, Sato H, Daw NW (1989) The location and function of NMDA receptors in cat and kitten visual cortex. J Neurosci 9:2445-2453.
Fox K, Schlaggar BL, Glazewski S, O'Leary DMM (1996) Glutamate blockade at cortical synapses disrupts development of thalamocortical and columnar organization in somatosensory cortex. Proc Natl Acad Sci USA 93:5584-5589.

Fox K, Glazewski S, Schulze S (2000) Plasticity and stability of somatosensory maps in thalamus and cortex. Curr Opin Neurobiol 10:494497.

Glazewski S, Fox K (1996) The time-course of experience-dependent synaptic potentiation and depression in barrel cortex of adolescent rats. J Neurophysiol 75:1714-1729.

Glazewski S, Chen CM, Silva A, Fox K (1996) Requirement for $\alpha$-CaMKII in experience dependent plasticity of the barrel cortex. Science 272:421-423.

Glazewski S, McKenna M, Jacquin M, Fox K (1998) Experiencedependent depression of vibrissae responses in rat barrel cortex. Eur J Neurosci 10:2107-2116.

Glazewski S, Giese KP, Silva A, Fox K (2000) The role of alphaCaMKII autophosphorylation in neocortical experience-dependent plasticity. Nat Neurosci 3:911-918.

Hata Y, Stryker MP (1994) Control of thalamocortical afferent rearrangement by postsynaptic activity in developing visual cortex. Science 265:1732-1735.

Hata Y, Tsumoto T, Stryker MP (1999) Selective pruning of more active afferents when cat visual cortex is pharmacologically inhibited. Neuron $22: 375-381$.

Kelly MK, Carvell GE, Kodger JM, Simons DJ (1999) Sensory loss by selected whisker removal produces immediate disinhibition in the somatosensory cortex of behaving rats. J Neurosci 19:9117-9125.

Krupa DJ, Ghazanfar AA, Nicolelis MA (1999) Immediate thalamic sensory plasticity depends on corticothalamic feedback. Proc Natl Acad Sci USA 96:8200-8205.

Li X, Glazewski S, Lin X, Elde R, Fox K (1995) The effect of vibrissae deprivation on follicle innervation, neuropeptide synthesis in the trigeminal ganglion and S1 barrel field cortical plasticity. J Comp Neurol 357:465-481.

Markram H, Lubke J, Frotscher M, Sakmann B (1997) Regulation of synaptic efficacy by coincidence of postsynaptic APs and EPSPs. Science 275:213-215.

Nicholson C, Phillips JM (1981) Ion diffusion modified by tortuosity and volume fraction in the extracellular microenvironment of the rat cerebellum. J Physiol (Lond) 321:225-257.

Parker JL, Dostrovsky JO (1999) Cortical involvement in the induction, but not expression, of thalamic plasticity. J Neurosci 19:8623-8629.

Polley DB, Chen-Bee CH, Frostig RD (1999) Two directions of plasticity in the sensory-deprived adult cortex. Neuron 24:623-637.

Reiter HO, Stryker MP (1988) Neural plasticity without postsynaptic action potentials: less-active inputs become dominant when kitten visual cortical cells are pharmacologically inhibited. Proc Natl Acad Sci USA 85:3623-3627.

Rema V, Armstrong-James M, Ebner FF (1998) Experience-dependent plasticity of adult rat S1 cortex requires local NMDA receptor activation. J Neurosci 18:10196-10206.

Simons DJ, Land PW (1987) Early experience of tactile stimulation influences organization of somatic sensory cortex. Nature 326:694-697.

Skibinska A, Glazewski S, Fox K, Kossut M (2000) Age dependent response of the mouse barrel cortex to sensory deprivation: a $2 \mathrm{DG}$ study. Exp Brain Res 132:143-148.

Wallace H, Fox K (1999a) The effect of chessboard deprivation pattern on potentiation and depression of vibrissae responses in rat barrel cortex. Somatosens Mot Res 16:122-138.

Wallace H, Fox K (1999b) Local cortical interactions determine the form of cortical plasticity. J Neurobiol 41:58-63.

Wong-Riley M (1979) Changes in the visual system of monocularly sutured or enucleated cats demonstrable with cytochrome oxidase histochemistry. Brain Res 171:11-28.

Woolsey TA, Van der Loos H (1970) The structural organization of layer IV in the somatosensory region (SI) of mouse cerebral cortex. The description of a cortical field composed of discrete cytoarchitectonic units. Brain Res 17:205-242. 